\title{
Stationary Eddies and the Zonal Asymmetry of Net Precipitation and Ocean Freshwater Forcing
}

\author{
ROBERT C. WILLS AND TAPIO SCHNEIDER \\ California Institute of Technology, Pasadena, California, and ETH Zurich, Zurich, Switzerland
}

(Manuscript received 16 August 2014, in final form 19 February 2015)

\begin{abstract}
Transport of water vapor in the atmosphere generates substantial spatial variability of net precipitation (precipitation minus evaporation). Over half of the total spatial variability in annual-mean net precipitation is accounted for by deviations from the zonal mean. Over land, these regional differences determine differences in surface water availability. Over oceans, they account, for example, for the Pacific-Atlantic difference in sea surface salinity, with implications for the deep overturning circulation. This study analyzes the atmospheric water budget in reanalyses from ERA-Interim and MERRA, to investigate which physical balances lead to zonal variation in net precipitation. It is found that the leading-order contribution is zonal variation in stationary-eddy vertical motion. Transient eddies modify the pattern of zonally anomalous net precipitation by moving moisture from the subtropical and tropical oceans onto land and poleward across the Northern Hemisphere storm tracks. Zonal variation in specific humidity and stationary-eddy horizontal advection play a secondary role. The dynamics leading to net precipitation via vertical motion in stationary eddies can be understood from a lowertropospheric vorticity budget. The large-scale variations of vertical motion are primarily described by Sverdrup balance and Ekman pumping, with some modification by transient eddies. These results suggest that it is important to understand changes in stationary eddies and their influence on the zonal variation of transient eddy fluxes, in order to understand regional changes in net precipitation. They highlight the relative importance of different atmospheric mechanisms for the freshwater forcing of the North Pacific and North Atlantic.
\end{abstract}

\section{Introduction}

The hydrological cycle is linked to the general circulation of the atmosphere by the transport of water vapor. Precipitation in the tropics occurs as easterly winds converge in the intertropical convergence zone (ITCZ), leading to the vertical motion and moisture transport that make up the ascending branch of the Hadley cell. In the subtropics, strong subsidence associated with the descending branch of the Hadley cell leads to a minimum in precipitation and a region of net evaporation. Beyond this dry zone, transient eddies transport water vapor into midlatitudes, where precipitation associated with transient storm track eddies is high, leading to positive net precipitation (precipitation minus evaporation, $P-E$ ). These are the basic mechanisms that govern the spatial variation of zonal-mean net precipitation. But the zonal mean accounts for only

Corresponding author address: Robert C. Wills, Geological Institute, ETH Zurich, Sonneggstrasse 5, 8092 Zurich, Switzerland. E-mail: rwills@caltech.edu
$40 \%$ of the total spatial variance of annual-mean net precipitation.

Accounting for the rest of this spatial variability, variations about the zonal-mean hydrological cycle take the form of extratropical stationary Rossby waves, dry subtropical lows, monsoons, storm tracks, and Walker circulations. Extratropical stationary Rossby waves are forced by interactions of the jet stream with topography or by the atmospheric response to ocean heat release or dynamical heating by transient eddies (Webster 1981; Hoskins and Karoly 1981; Held et al. 2002). They are important for the maintenance of wet and dry zones over North America and Asia (Broccoli and Manabe 1992), especially in Northern Hemisphere winter. Dry subtropical lows over oceans are associated with upstream Rossby wave propagation from topographic sources (Takahashi and Battisti 2007) or monsoon heating (Rodwell and Hoskins 1996, 2001) and play a role in steering weather patterns that travel across ocean basins. Monsoons are highly seasonal wet zones associated with low-level wind reversals that are part of a seasonal restructuring of the subtropical meridional overturning 
circulation (Webster et al. 1998; Bordoni and Schneider 2008), which can be amplified locally by topographic blocking of moisture and energy fluxes (Boos and Kuang 2010). Zonal variation in storm track precipitation governs the climates of midlatitude coastal regions and forces ocean basin asymmetry in salinity and deep overturning (Warren 1983, hereafter W83; Emile-Geay et al. 2003, hereafter EG03; Ferreira et al. 2010). Walker circulations are associated with zonally asymmetric ocean heat flux convergence in the tropics, leading to a region of high evaporation and strong deep convection, for instance in the Pacific warm pool (Gill 1980; Neelin 1988; Philander 1990).

Circulation patterns are tightly coupled to precipitation. Betts (1998) and Held and Soden (2006) suggest that global-mean precipitation can be thought of as a product of the global upward mass transport by all atmospheric circulations and a representative boundary layer moisture content. Similarly, the magnitude of variation in net precipitation with latitude can be directly tied to the strength of the zonal-mean general circulation. O'Gorman and Schneider (2008) show that subtropical net evaporation due to mean-flow moisture divergence scales with the strength of the Hadley cell and a measure of tropical moisture content. They also relate net precipitation in midlatitudes due to transient-eddy moisture flux convergence to the energy of transient eddies. Can zonally anomalous net precipitation similarly be tied to the strength of zonally anomalous circulations?

Broccoli and Manabe (1992) show in a GCM that the presence of orography is important for maintaining midlatitude dry zones, which occur west of the troughs of orographically forced stationary Rossby waves. Similarly, dry zones can form associated with troughs of Rossby waves propagating upstream from regions of monsoon heating, which may partially account for the aridity of subtropical deserts (Rodwell and Hoskins 1996, 2001).

While dry zones are associated with regions of low-level mass divergence in stationary Rossby waves, wet zones are often associated with regions of convergence. Several studies point to the role of lower-tropospheric flow convergence downstream of Tibet in setting the strength and spatial extent of the strong East Asian monsoon precipitation in early summer (Molnar et al. 2010; Chen and Bordoni 2014). Here we show using reanalyses that the same mechanisms apply to both wet and dry zones and that the lower-tropospheric stationary-eddy mass flux convergence can be used to gain quantitative insight into the magnitude of wet and dry zones globally.

Lower-tropospheric stationary-eddy mass flux convergence leads to vertical motion and vortex stretching, which must be compensated in a steady state by a sink of absolute vorticity. We analyze the zonally anomalous vorticity budget in reanalysis to gain insight into the balances that can sustain this vertical motion. We find that meridional advection of planetary vorticity and surface drag are the primary contributors. This relates the hydrologically relevant stationary-eddy vertical motion to the large-scale horizontal flow of the stationary eddies. Tools for understanding the response of stationary Rossby waves to large-scale forcing by heating and orography [e.g., Hoskins and Karoly 1981; see reviews by Held (1983) and Held et al. (2002)] can thus be applied directly to understanding the zonal variation of net precipitation.

We use reanalyses from ERA-Interim and MERRA for this study as detailed in section 2. In section 3, we discuss a decomposition of the zonally anomalous moisture budget, leading to the conclusion that vertical motion in stationary eddies sets the predominant pattern of net precipitation, while transient eddies and horizontal advection partially cancel, with the net effect of bringing moisture onto land and poleward across the storm tracks. In section 4, we discuss the dynamics leading to vertical motion in stationary eddies using an analysis of the lowertropospheric zonally anomalous vorticity budget. In section 5, we discuss the role of these mechanisms in shaping the asymmetry of sea surface salinity between the North Atlantic and North Pacific, expanding on several other studies that have looked at atmospheric control of northern high-latitude salinity asymmetries (e.g., W83; EG03; Ferreira et al. 2010; Nilsson et al. 2013). In section 6 , we provide an overview of the mechanistic picture these physical balances leave us with.

It is worth emphasizing from the outset that in simplifying the zonally anomalous moisture and vorticity budgets to their essential components we seek not to obtain a complete quantitative picture, but rather to provide insight into dominant mechanisms.

\section{Data and methods}

Moisture and vorticity budgets are analyzed using the European Center for Medium-Range Weather Forecasts (ECMWF) interim reanalysis (ERA-Interim) products $\left(1.5^{\circ}\right)$ (Dee et al. 2011). Surface fields are averaged from four-times-daily 6- and 12-h forecast fields produced from forecasts beginning at 0000 and 1200 UTC. Data on pressure levels are averaged from four-times-daily analyzed fields produced at 0000 , 0600,1200 , and 1800 UTC on 37 unevenly spaced pressure levels. All analyses are done on 1979-2012 climatologies; we checked subsets of this time period for robustness of the results.

Comparisons of the water cycle between multiple reanalysis projects (Trenberth et al. 2007, 2011) show 
that they all tend to have unphysical regions of net evaporation over land, trends associated with changes of observing system, and an overestimated magnitude of water cycling over oceans (affecting precipitation $P$ and evaporation $E$ but not $P-E$ ). We are interested in the large-scale balance of terms, which are generally reasonable in reanalyses and should be unaffected by these quantitative issues. All analyses shown here for ERAInterim were repeated for the NASA Global Modeling and Assimilation Office MERRA (1.5 ) (Rienecker et al. 2011) using surface data and data assimilated on 42 pressure levels.

Trenberth et al. (2002) point out issues that can arise when analyzing vertically integrated budgets in reanalyses on pressure levels, where information from pressure levels that are not always present is incorporated via vertical interpolation. Both ERA-Interim and MERRA publish vertically integrated moisture fluxes, which we use to calculate the total moisture flux convergence. However, decomposition of the total flux into stationary and transient components requires additional vertical integrations of different flux components. We checked the robustness of our results between ERA-Interim's interpolated pressure coordinate product, ERA-Interim's hybrid model coordinate product, and MERRA's pressure coordinate product. The large-scale balances are the same irrespective of vertical coordinate system or dataset used, but significant differences exist between pressure and hybrid-coordinate fields directly over topography. These differences cannot be disentangled from the different definitions of stationary and transient eddies in different vertical coordinate systems. All figures show fields from ERA-Interim pressure coordinate and surface fields. Tables show values for both ERA-Interim and MERRA.

To study the influence of zonal variation in net precipitation on ocean freshwater input, a river network dataset must be used to route net precipitation from the continents into the appropriate ocean drainages. We use the Simulated Topological Network (STN-30P) $0.5^{\circ}$ river topology dataset (Fekete et al. 2001; Vörösmarty et al. 2000). This river network model gives the river outlet location for each land point. We make no attempt to account for water storage in the drainage system. This is a justifiable assumption for the annual mean but not for seasonal variations in freshwater forcing.

\section{Moisture budget}

We examine the moisture budget in the present climate using ERA-Interim and MERRA. The total net precipitation, $P-E$, is shown in Fig. 1 for ERA-Interim. We focus in particular on understanding the mechanisms for

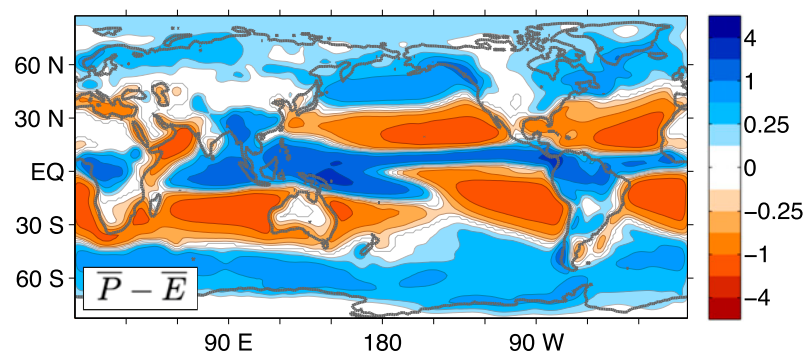

FIG. 1. Annual-mean net precipitation $(P-E)$ from ERAInterim. Here and in all subsequent figures, the fields are smoothed with a $1.5^{\circ}$ real-space Gaussian filter to remove smallscale noise. The color bar is logarithmic, with factors of 2 between contour levels. All absolute values less than $0.125 \mathrm{~m} \mathrm{yr}^{-1}$ are white, with a gray contour separating positive and negative values.

zonally anomalous net precipitation (Fig. 2e), which accounts for $60 \%$ of the spatial variance in the total $P-E$. By definition, the zonal mean $P-E$ (Fig. 2f) accounts for the remaining $40 \%$.

The zonal variation of $P-E$ primarily shows zonal variation of precipitation (Fig. 2a), especially over oceans. Zonal variation of evaporation (Fig. 2c) shows moisture limitation in dry land areas and evaporative cooling of warm ocean waters in the western boundary currents.

The moisture budget provides a tool to analyze the flow patterns associated with spatial variation in $P-E$, avoiding complexities associated with studying precipitation or evaporation independently. As net precipitation is the only substantial source/sink of atmospheric water vapor, in steady state it must be equal to the time mean convergence of water vapor flux,

$$
\bar{P}-\bar{E}=-\nabla \cdot\langle\overline{\mathbf{u}} q\rangle .
$$

Here $\boldsymbol{\nabla}$ is the nabla operator on a sphere, $\mathbf{u}=(u, v)$ is the horizontal wind, $q$ is the specific humidity, and $\langle\cdot\rangle$ denotes a density weighted vertical integral over the atmospheric column,

$$
\langle\cdot\rangle=\int_{0}^{\bar{p}_{s}}(\cdot) \frac{d p}{g} .
$$

Any vertical integral between limits $a$ and $b$ other than between $0 \mathrm{hPa}$ and the full time-mean surface pressure, $\bar{p}_{s}$, will be denoted by $\langle\cdot\rangle_{a}^{b}$. This framework for studying moisture flux convergence as a measure of $P-E$ has been used in numerous studies of the hydrological cycle (Peixoto and Oort 1983, 1992; Held and Soden 2006; Trenberth et al. 2007, 2011; Seager et al. 2007, 2010, 2014; Newman et al. 2012). 

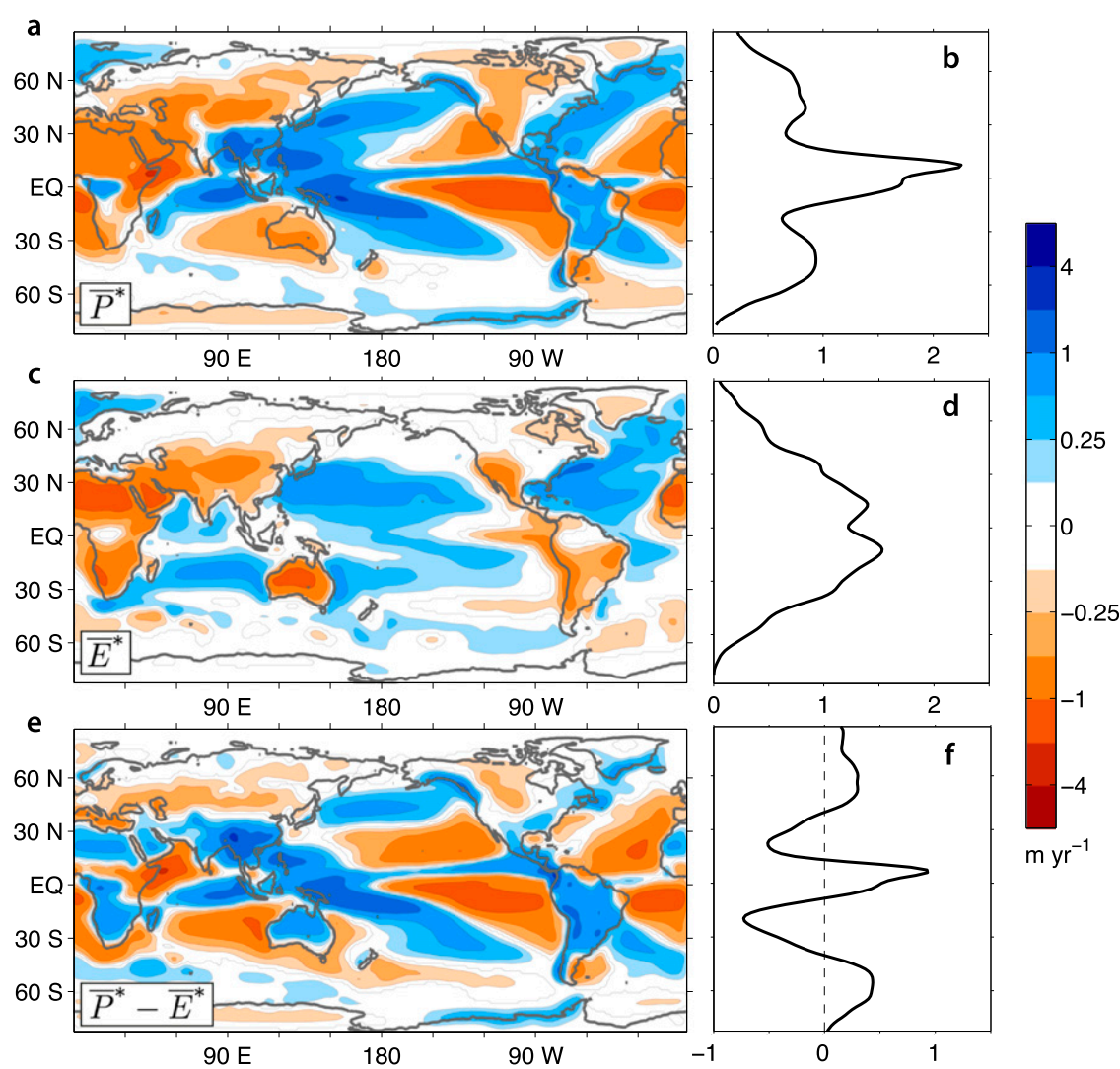

FIG. 2. Annual-mean hydrological cycle from ERA-Interim: (a),(b) precipitation $\bar{P}$, (c),(d) evaporation $\bar{E}$, and (e),(f) $\bar{P}-\bar{E}$. The full fields are decomposed into (left) zonally anomalous components and (right) zonal-mean components.

To simplify the treatment of surface pressure gradients, we take the divergence operator inside the vertical integral and leave all effects of surface pressure gradients that arise from differentiating the limits of integration in a separate surface term,

$$
\bar{S} \equiv \nabla \cdot\langle\overline{\mathbf{u} q}\rangle-\langle\nabla \cdot \overline{\mathbf{u} q}\rangle=\left.\overline{\mathbf{u} q}\right|_{\mathrm{sfc}} \cdot \nabla p_{s} .
$$

Therefore,

$$
\bar{P}-\bar{E}=-\langle\nabla \cdot \overline{\mathbf{u} q}\rangle-\bar{S} .
$$

This differs slightly from the methodology of Newman et al. (2012), who keep the surface term in the advective portion of the moisture convergence. Our methodology avoids creating large canceling moisture flux convergences and divergences in the following stationary-eddy decomposition, which arise as moisture flux impinging on topography is converted into moisture flux around the topography. Physically, the surface term is the result of near-surface moisture fluxes moving along surface pressure gradients or across surface pressure contours. It is small away from topography. See appendix A for further details on the reasoning for introducing this term.

By Reynolds' decomposition of the time-mean moisture flux, the climatology of $P-E$ on monthly or longer time scales can be understood as the sum of the effects of moisture convergence by the time mean flow and by transient eddies. We use $(\cdot)^{\prime}$ to denote deviations from the time mean, $\overline{(\cdot)}$, such that $(\cdot)=\overline{(\cdot)}+(\cdot)^{\prime}$ and

$$
\bar{P}-\bar{E}=-\left\langle\nabla \cdot\left(\overline{\mathbf{u}} \bar{q}+\overline{\mathbf{u}^{\prime} q^{\prime}}\right)\right\rangle-\bar{S} .
$$

See appendix A for details on the treatment of surface pressure fluctuations. The transient eddy term $\left(\overline{\mathbf{u}^{\prime} q^{\prime}}\right)$ includes all correlations between $\mathbf{u}$ and $q$ that are not represented in their annual-mean climatologies (i.e., including seasonal correlations). Newman et al. (2012) include a discussion of how this transient-eddy moisture flux is split into synoptic variability (with frequency less than 10 days) and low-frequency variability.

At this point, it is useful to split the moisture budget into zonal-mean and zonally anomalous components, 
TABLE 1. Correlation of $1.5^{\circ}$ Gaussian filtered moisture flux convergence terms with $\bar{P}-\bar{E}\left(\rho_{P-E}\right)$ and global-mean spatial standard deviation, $\sigma$, for each field. ERA-Interim and MERRA (in parentheses) are both shown.

\begin{tabular}{|c|c|c|c|c|c|c|c|}
\hline & $\bar{P}-\bar{E}$ & $\overline{[P]}-\overline{[E]}$ & $\bar{P}^{*}-\bar{E}^{*}$ & $-\left\langle\nabla_{y} \cdot([\overline{\mathbf{u}}][\bar{q}])\right\rangle$ & $-\left\langle\nabla \cdot \overline{\mathbf{u}^{\prime} q^{\prime}}\right\rangle$ & $-\left\langle\nabla \cdot\left(\overline{\mathbf{u}}^{\dagger} \bar{q}^{\dagger}\right)\right\rangle$ & $\bar{S}$ \\
\hline$\rho_{P-E}$ & $\mathrm{n} / \mathrm{a}$ & $0.65(0.60)$ & $0.76(0.80)$ & $0.61(0.53)$ & $0.03(0.05)$ & $0.61(0.54)$ & $0.26(0.11)$ \\
\hline$\sigma\left(\mathrm{m} \mathrm{yr}^{-1}\right)$ & $0.72(0.62)$ & $0.47(0.37)$ & $0.54(0.50)$ & $0.43(0.40)$ & $0.28(0.37)$ & $0.63(0.66)$ & $0.23(0.40)$ \\
\hline
\end{tabular}

to analyze these portions separately. We use $(\cdot)^{*}$ to denote deviations from the zonal mean, $[\cdot]$, such that $(\cdot)=[\cdot]+(\cdot)^{*}$. The zonal-mean moisture budget can be written as ${ }^{1}$

$$
\overline{[P]}-\overline{[E]}=-\left\langle\nabla_{y} \cdot\left(\left[\overline{\bar{u}^{\prime} q^{\prime}}\right]+[\overline{\mathbf{u}}][\bar{q}]+\left[\overline{\mathbf{u}}^{*} \bar{q}^{*}\right]\right)\right\rangle_{0}^{\left[\bar{p}_{s}\right]}-\overline{[S]}
$$

where $\nabla_{y}$ is shorthand for the meridional component of $\nabla$. The zonally anomalous moisture budget can be written as

$$
\bar{P}^{*}-\bar{E}^{*}=-\left\langle\nabla \cdot\left(\overline{\mathbf{u}^{\prime} q^{\prime}}+[\overline{\mathbf{u}}][\bar{q}]+\overline{\mathbf{u}}^{\dagger} \bar{q}^{\dagger}\right)\right\rangle^{*}-\bar{S}^{*},
$$

where

$$
\overline{\mathbf{u}}^{\dagger} \bar{q}^{\dagger} \equiv \overline{\mathbf{u}}^{*}[\bar{q}]+[\overline{\mathbf{u}}] \bar{q}^{*}+\overline{\mathbf{u}}^{*} \bar{q}^{*}
$$

is the sum of all terms involving stationary eddies, including the interactions of stationary eddies $(\cdot)^{*}$ with the zonal mean [·] (cf. Kaspi and Schneider 2013). Only the last of the three terms in Eq. (8), representing the traditional stationary eddy flux, contributes to the zonal mean. In this framework, stationary eddy contributions include both zonally anomalous flow patterns $\left(\overline{\mathbf{u}}^{*}\right)$ and the zonal variations in moisture $\left(\bar{q}^{*}\right)$ that result from these circulations. The zonal-mean moisture flux also shows up in the zonally anomalous moisture budget due to zonal variations in surface pressure, which influence the vertical integration. The relative contributions of the terms of Eqs. (6) and (7) to the total spatial variance in $P-E$ are tabulated in Table 1.

The zonal-mean moisture budget is analyzed in terms of Eq. (6) in Peixoto and Oort (1992). In low latitudes it is dominated by the Hadley cell, which has an equatorward surface branch, resulting in the removal of moisture from the subtropics and convergence in the ITCZ. This is represented by $-\nabla_{y} \cdot([\overline{\mathbf{u}}][\bar{q}])$ and is plotted in Fig. 3f. Beyond the zero of the mean-flow moisture flux

\footnotetext{
${ }^{1}$ By taking the vertical integral with the zonal-mean surface pressure, we are ignoring terms due to the zonal correlation of moisture fluxes and surface pressure, which are small $\left(\sim 10^{-6} \mathrm{~m} \mathrm{yr}^{-1}\right)$.
}

at approximately $30^{\circ}$, the moisture flux convergence is dominated by transient eddies, which transport moisture from the subtropics and tropics to the midlatitude storm tracks, leading to rainfall associated with synoptic variability. Figure $3 \mathrm{~d}$ shows the contribution of transient eddies to $\overline{[P]}-\overline{[E]}$. Stationary eddies also contribute to the zonal-mean hydrological cycle via the correlation of zonal variations in circulation and moisture, $-\nabla_{y} \cdot\left[\overline{\mathbf{u}}^{*} \bar{q}^{*}\right]$, which is shown in Fig. 3b.

Scaling relations for changes in zonal-mean precipitation with climate change (O'Gorman and Schneider 2008) start with an understanding of which terms of Eq. (6) are dominant in the climate system. By decomposing the zonally anomalous moisture budget into the terms of Eqs. (7) and (8), we hope to provide similar insight into which components of the circulation need to be understood in order to understand $\bar{P}^{*}-\bar{E}^{*}$ across different climates. This is relevant in light of recent studies (e.g., Seager et al. 2007, 2010, 2014), which show that changes in circulation can be as important as changes in atmospheric water vapor content for regional hydroclimate change.

The total zonally anomalous moisture flux can first be separated into that due to stationary eddies $\left(\overline{\mathbf{u}}^{\dagger} \bar{q}^{\dagger}\right.$; Fig. 3a), that due to transient eddies ( $\overline{\mathbf{u}^{\prime} q^{\prime}}$; Fig. 3c), that due to correlations of the zonal-mean flow $([\overline{\mathbf{u}}][\bar{q}])$ with zonal variations of surface pressure (Fig. 3e), and that due to the surface term defined in Eqs. (3) and (A8) $\left(\bar{S}^{*}\right.$; Fig. $3 \mathrm{~g})$. We find that the stationary-eddy moisture flux convergence (Fig. 3a) is leading order in setting the pattern of $\bar{P}^{*}-\bar{E}^{*}$, as can be seen, for example, in its strong correlation with $\bar{P}^{*}-\bar{E}^{*}$ (Table 2). In many regions of the globe, especially over oceans, transient eddies provide a negative feedback by transporting water vapor down moisture gradients set up by the stationary eddies, to reduce zonal variation in moisture. This is an expected result as transient eddies have been observed to cause downgradient moisture fluxes in a wide range of climates (Caballero and Langen 2005; O'Gorman and Schneider 2008).

The zonally anomalous transient-eddy moisture flux convergence (Fig. 3c) is large in several coastal land areas that are dried by the stationary eddy fluxes, such as California, Chile, and northern China. This is consistent with what is found in other studies 

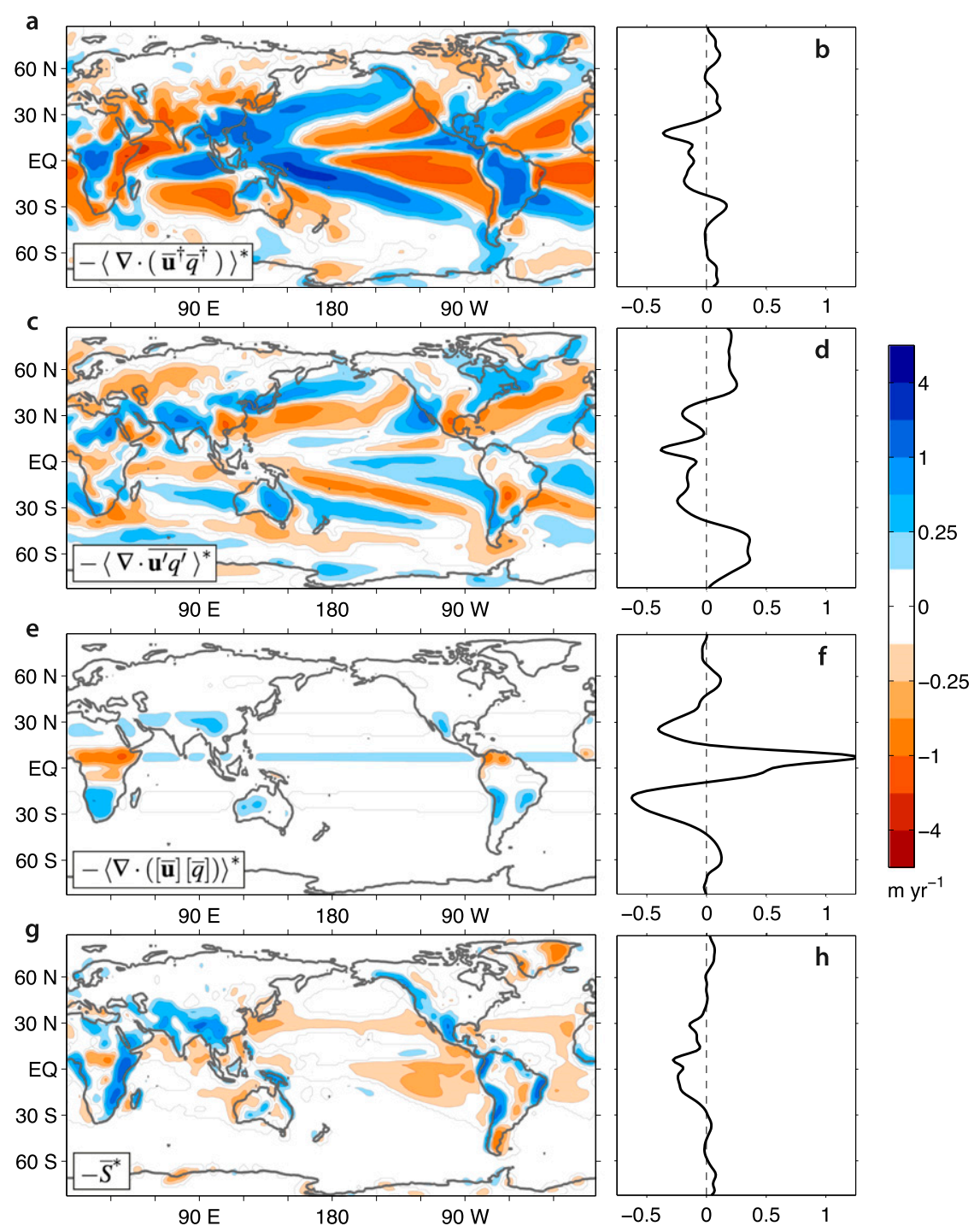

FIG. 3. Contributions to the column-integrated moisture flux convergence from (a), (b) stationary eddies, (c),(d) transient eddies, (e),(f) the zonal-mean circulation, and (g), (h) the surface term as defined in the text. The full fields are decomposed into (left) zonally anomalous components and (right) zonal-mean components.

(e.g., Newman et al. 2012) where synoptic and low-frequency variability is seen to be a major influence on moisture transport from ocean to land. Some of the transient eddy transport, especially in monsoonal areas, is accomplished by seasonal correlations, which are not always considered as transient eddies and are therefore shown separately in Fig. 4. This term is calculated using a Reynolds' decomposition on monthly means. Transient eddy fluxes also provide a large contribution to $\bar{P}^{*}-\bar{E}^{*}$ in the Northern Hemisphere storm tracks through strong local meridional moisture fluxes, as is well established (see, e.g., Peixoto and Oort 1992). Overall, transient-eddy moisture flux convergence has a weak negative correlation with $\bar{P}^{*}-\bar{E}^{*}$ (Table 2).

The contribution of the convergence of the zonalmean moisture flux $([\overline{\mathbf{u}}][\bar{q}])$ to $\bar{P}^{*}-\bar{E}^{*}$ (Fig. 3e), through the zonal variation of surface pressure (and thus the total mass of the atmospheric column) is small, except in a few regions of low surface pressure (high surface elevation). In these regions, the moistening of the ITCZ and the drying of the Hadley cell subsidence zone are not felt as strongly because some of the (higher) pressure levels used in calculating the zonal mean, and 
TABLE 2. Correlation of $1.5^{\circ}$ Gaussian filtered zonally anomalous moisture flux convergence terms with $\bar{P}^{*}-\bar{E}^{*}\left(\rho_{P^{*}-E^{*}}\right)$ and globalmean spatial standard deviation, $\sigma$, for each field. Compare $\sigma$ with that for $\bar{P}^{*}-\bar{E}^{*}$ in Table 1. ERA-Interim and MERRA (in parentheses) are both shown.

\begin{tabular}{lcccccrr}
\hline \hline & $-\left\langle\nabla \cdot\left(\overline{\mathbf{u}}^{\dagger} \bar{q}^{\dagger}\right)\right\rangle^{*}$ & $-\left\langle\nabla \cdot \overline{\mathbf{u}^{\prime} q^{\prime}}\right\rangle^{*}$ & $-\langle[\bar{q}] \boldsymbol{\nabla} \cdot \overline{\mathbf{u}}\rangle^{*}$ & $-\left\langle\overline{\mathbf{u}} \cdot \nabla_{y}[\bar{q}]\right\rangle^{*}$ & $-\left\langle\overline{\mathbf{u}} \cdot \nabla \bar{q}^{*}\right\rangle^{*}$ & $-\left\langle\overline{\mathbf{u}} \cdot \nabla \bar{q}+\nabla \cdot \overline{\mathbf{u}^{\prime} q^{\prime}}\right\rangle^{*}$ & $\bar{S}^{*}$ \\
\hline$\rho_{P^{*}-E^{*}}$ & $0.81(0.69)$ & $-0.16(-0.15)$ & $0.85(0.72)$ & $0.42(0.41)$ & $0.22(0.32)$ & $0.23(0.22)$ & $0.34(0.21)$ \\
$\sigma\left(\mathrm{m} \mathrm{yr}^{-1}\right)$ & $0.61(0.64)$ & $0.28(0.30)$ & $0.52(0.53)$ & $0.18(0.19)$ & $0.25(0.35)$ & $0.23(0.34)$ & $0.20(0.38)$ \\
\hline
\end{tabular}

important for the moisture budget, lie below the topography. This effect contributes to the relative dryness of equatorial Africa and South America and the relative wetness of northern and southern Africa in our analysis on pressure levels. We will consider this a stationary-eddy term for the rest of the text.

The surface term $\bar{S}^{*}$ is most significant over high topography, but also significantly contributes to the moistening of most coastal areas. It represents orographic precipitation as the flow rises over topography. To a lesser extent, this term also shows descent and dryness downstream from topography (e.g., the eastern sides of the Rockies, Patagonia, and Greenland). Over the oceans, the surface term shows moisture transport out of high pressure regions such as the Pacific cold tongue. The residual of Eq. (7) associated with errors in the reanalysis and discretization of the vertical integration is not significant to this analysis and is wrapped into the surface term (Fig. $3 \mathrm{~g}$ ), which has 10 times the spatial variance of the residual.

We seek to understand which portion of Eq. (8) explains the large contribution of stationary-eddy moisture fluxes to $\bar{P}^{*}-\bar{E}^{*}$. Specifically, we would like to understand the following:

1) Is the zonal variation of specific humidity, $\bar{q}^{*}$, an important influence on regional hydroclimate?

2) Does $\bar{P}^{*}-\bar{E}^{*}$ arise from stationary-eddy horizontal advection or vertical motion (horizontal divergence)?
For this purpose, we write the time-mean moisture flux convergence as

$$
\begin{aligned}
-\left\langle\nabla \cdot\left(\overline{\mathbf{u}}^{\dagger} \bar{q}^{\dagger}+[\overline{\mathbf{u}}][\bar{q}]\right)\right\rangle^{*}= & -\left\langle[\bar{q}] \nabla \cdot \overline{\mathbf{u}}+\overline{\mathbf{u}} \cdot \nabla_{y}[\bar{q}]\right. \\
& \left.+\bar{q}^{*} \nabla \cdot \overline{\mathbf{u}}+\overline{\mathbf{u}} \cdot \nabla \bar{q}^{*}\right\rangle^{*} .
\end{aligned}
$$

Here the first and second terms on the right-hand side are the portion of the stationary-eddy moisture flux convergence that does not include $\bar{q}^{*}$, addressing question 1 . The first and third terms are the vertical motion contribution of the stationary eddies to the moisture flux convergence, addressing question 2 . Figure 5 shows this decomposition of the stationary-eddy moisture flux convergence.

The stationary-eddy vertical advection of zonal-mean moisture, $-\langle[\bar{q}] \nabla \cdot \overline{\mathbf{u}}\rangle^{*}$ (Fig. 5a), is seen to be the dominant term. Vertical advection of zonally anomalous moisture, $-\left\langle\bar{q}^{*} \nabla \cdot \overline{\mathbf{u}}\right\rangle^{*}$ (Fig. 5b), is seen to enhance this vertical advection-based pattern of $\bar{P}^{*}-\bar{E}^{*}$ over oceans due to relatively high moisture content and reduce it over land due to moisture limitation. This term can be neglected, except over Africa where moisture limitation apparently plays an important role. The horizontal moisture advection terms shown in Figs. 5c,d, while smaller than the vertical moisture flux, are clearly not negligible. However, the sum of these, $-\langle\overline{\mathbf{u}} \cdot \nabla \bar{q}\rangle^{*}=-\left\langle\overline{\mathbf{u}} \cdot \nabla_{y}[\bar{q}]+\left(\overline{\mathbf{u}} \cdot \nabla \bar{q}^{*}\right)\right\rangle^{*}$, the total horizontal moisture advection by stationary eddies (Fig. 6a), is seen to be nearly out of phase with the transient-eddy moisture flux convergence (Fig. 3c). This suggests that

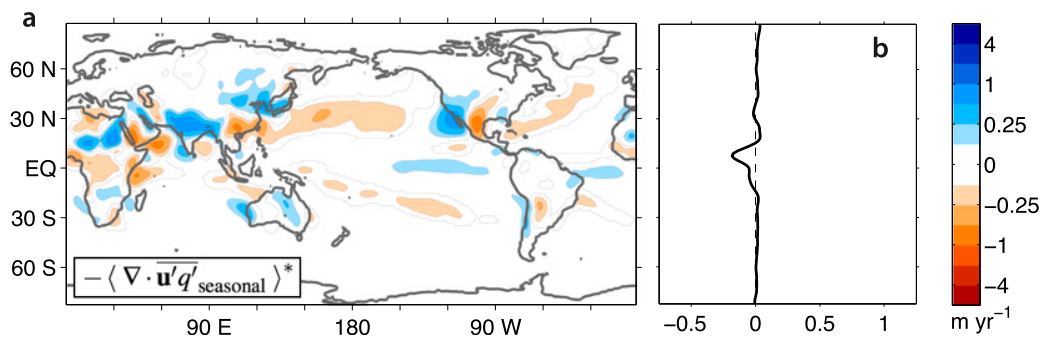

FIG. 4. Contributions to the column-integrated moisture flux convergence from the seasonal cycle, determined from deviations of monthly means from annual means. The full field is decomposed into (a) a zonally anomalous component and (b) a zonal-mean component. 

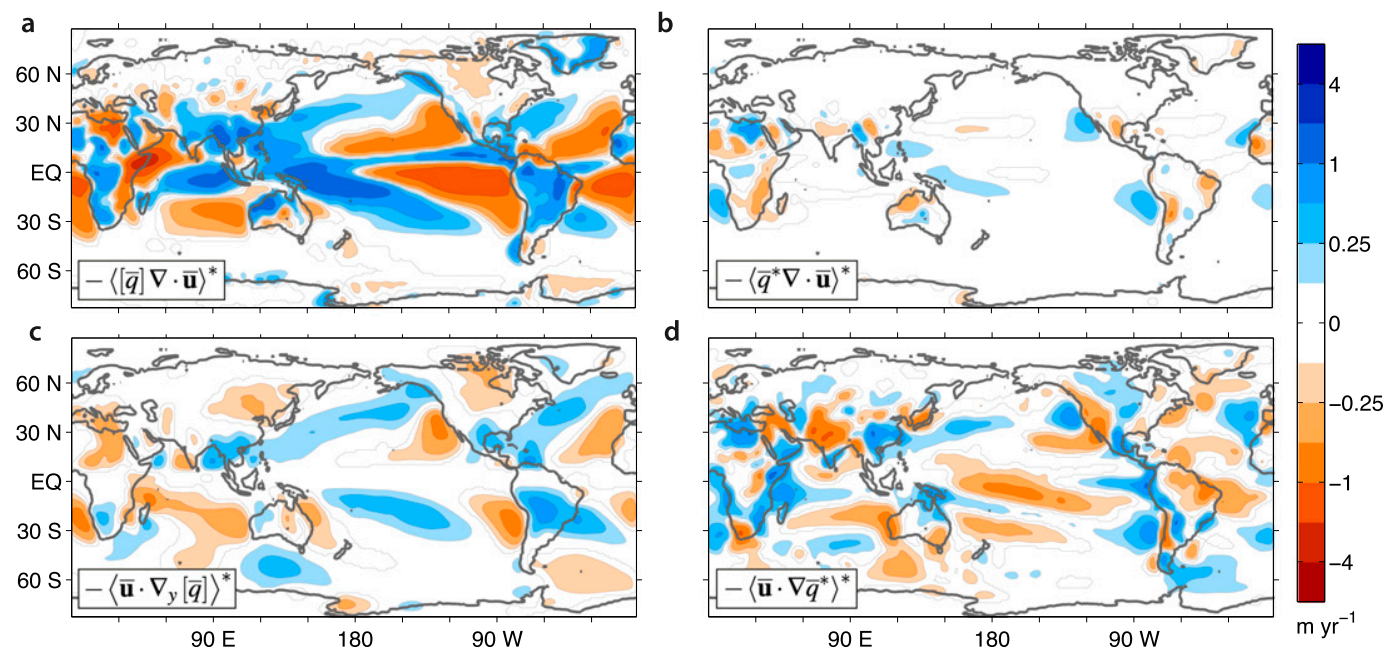

FIG. 5. Contributions to column-integrated moisture flux convergence by stationary eddies from (a) vertical advection of zonal mean specific humidity, (b) vertical advection of zonally anomalous specific humidity, (c) horizontal advection of zonal mean specific humidity, and (d) horizontal advection of zonally anomalous specific humidity. The small moisture flux convergence due to correlations of the zonalmean moisture flux with zonal variations of surface pressure is included in (a) and (c) as reflected in the notation.

transient eddies transport moisture down moisture gradients set up by time-mean horizontal advection (cf. Couhert et al. 2010), leading to a partial cancellation of these terms. The sum of the advective and transient terms (Fig. 6b) can be thought of as the net effect of horizontal advection and transient eddies on $\bar{P}^{*}-\bar{E}^{*}$, after accounting for their internal cancellation. The primary net influence is to bring moisture from the subtropical and tropical oceans into coastal regions and the equatorial Pacific cold tongue, and across the Northern Hemisphere storm tracks.

To summarize, zonal variation in $P-E$ comes about primarily from vertical motion in stationary eddies. Zonal variation of specific humidity has only a small influence on the vertical moisture flux, but it plays a role in the zonal variation of horizontal moisture fluxes and the zonal variation of transient-eddy moisture flux convergence. Together, horizontal advection and transient eddies primarily act to increase moisture convergence and $P-E$ on land, in the equatorial Pacific cold tongue, and in the North Pacific storm track. The corresponding moisture flux divergence is spread over most of the subtropical and tropical oceans where the reduction of $P-E$ due to horizontal and transient fluxes is less than $0.5 \mathrm{~m} \mathrm{yr}^{-1}$ in most areas. Computing a global-mean correlation (Table 2), the dominant term involving vertical advection of zonal-mean specific humidity accounts for half (MERRA) to nearly three-quarters (ERA-Interim) of the total spatial variance in $\bar{P}^{*}-\bar{E}^{*}$. The low correlation coefficient for the combined transient eddy and horizontal advection term is consistent with its lesser and more regional importance.

The relative importance of stationary-eddy vertical velocities versus transient-eddy moisture flux convergence remains season by season, as shown in Fig. 7. The seasonal moisture budget balance shown here is also described in Seager et al. (2014), for the particular case of

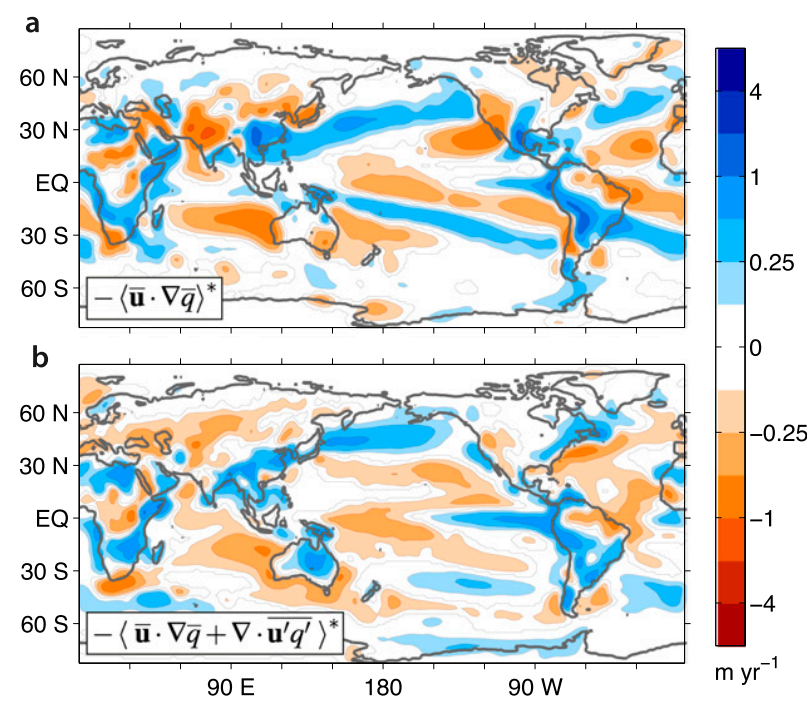

FIG. 6. (a) Total contribution of horizontal advection to the stationary-eddy moisture flux convergence. This is the sum of the terms in Figs. 5c and 5d. (b) Sum of the horizontal advection and transient eddy contributions to the zonally anomalous moisture flux convergence. This is the sum of the terms in Figs. 6a and 3c. 

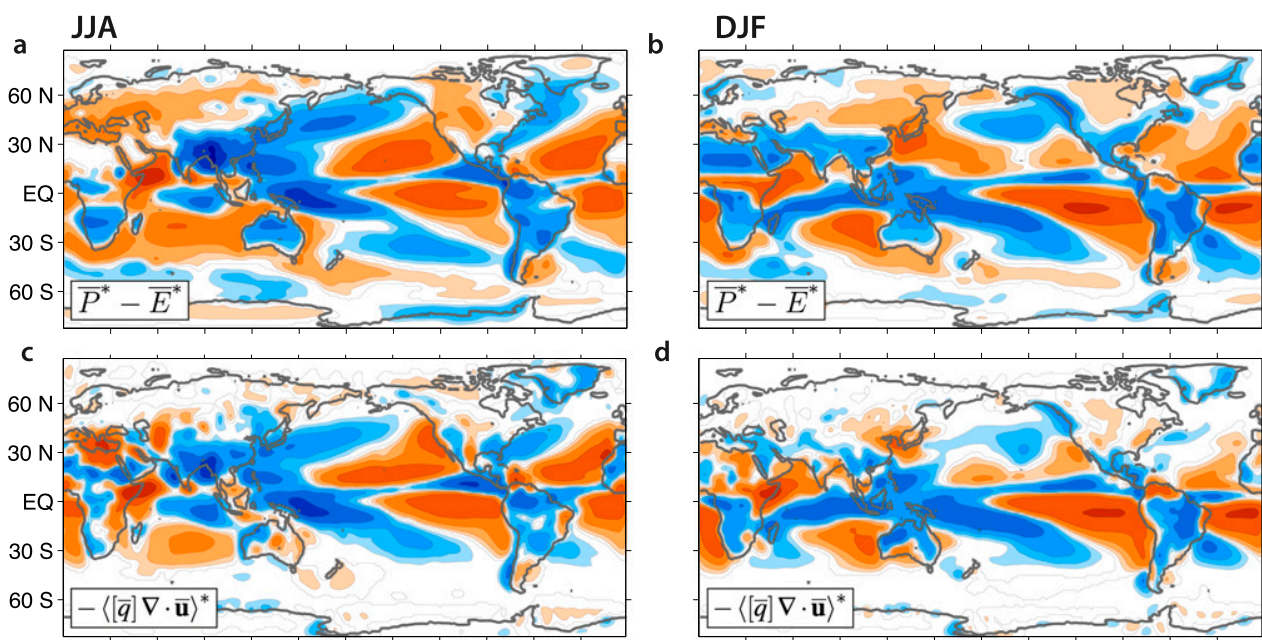

d
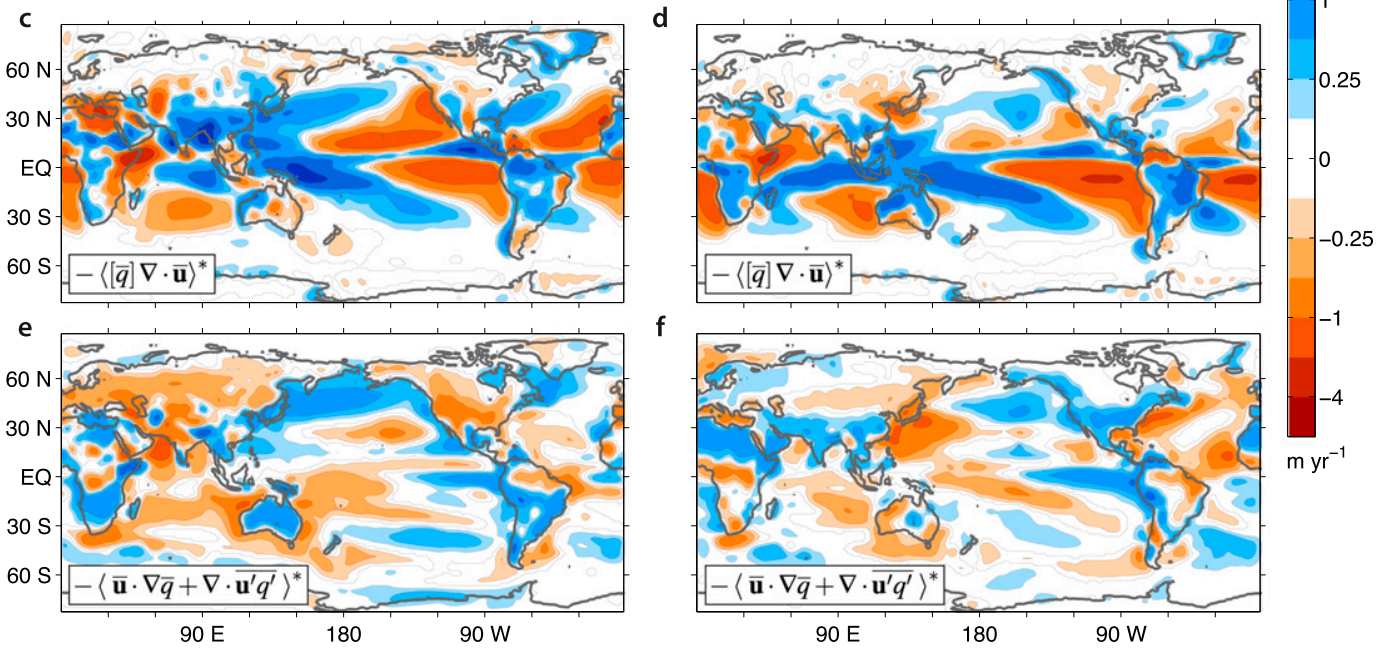

$f$

FIG. 7. (a),(c),(e) Moisture budget terms for JJA. (b),(d),(f) Moisture budget terms for DJF.

the Mediterranean region, with drying by stationary-wave subsidence in the summer and a balance of transient-eddy moisture flux convergence and stationary-eddy advection in the winter. They then use these results to explain the predicted drying in both seasons over the next 20 years in CMIP5 simulations, illustrating the practicality of this approach. The results in Fig. 7 can also be used to confirm, for example, the well-known relation between Indian and East Asian monsoon rainfall and strong summer vertical motion.

\section{Dynamics of stationary-eddy vertical motion}

The moisture budget analysis indicates that zonal patterns in net precipitation result primarily from zonal variations in lower-tropospheric vertical velocities associated with stationary eddies. Hence, it is important to understand which physical mechanisms lead to these zonal variations in vertical velocity. While condensation of water vapor during convection can play a role in amplifying or damping vertical motion (Emanuel et al. 1994), the physics of lower-tropospheric vertical motion can mostly be thought of as external to this convective heating. We seek insight into the dynamics of vertical motion in stationary eddies via the lower-tropospheric vorticity budget.
To this end, we must understand which portion of the lower troposphere is important for determining the vertical motion that contributes to $\bar{P}^{*}-\bar{E}^{*}$. Using the integral form of the mean value theorem, the flow divergence term of the zonally anomalous moisture budget can be approximated as

$$
\langle[\bar{q}] \nabla \cdot \overline{\mathbf{u}}\rangle^{*}=\left[\bar{q}_{\mathrm{sfc}}\right]\left(\langle\boldsymbol{\nabla} \cdot \overline{\mathbf{u}}\rangle_{p_{i}}^{\bar{s}_{s}}\right)^{*},
$$

where $\bar{q}_{\text {sfc }}$ is the surface specific humidity and $p_{i}$ is some pressure level in the vertical domain. By continuity, and using the fact that the vertical velocity is zero at a flat surface, $\langle\nabla \cdot \overline{\mathbf{u}}\rangle_{p_{i}}^{p_{s}}$ corresponds to a vertical velocity at $p_{i}$.

Equation (10) is exact for some value of $p_{i}$, but is approximate when using one value of $p_{i}$ globally. Since specific humidity falls off rapidly with height, this is a good approximation for $p_{i}$ between about 950 and $400 \mathrm{hPa}$. We obtain a global mean best fit $p_{i}$ of $850 \mathrm{hPa}$ by solving for $p_{i}$ at each grid point and then taking an area-weighted global mean. It corresponds to an altitude of about $1.5 \mathrm{~km}$, thus lying below the water vapor-scale height of about $2.3 \mathrm{~km}$, as one would expect. This value matches well with the level of maximum vertical moisture flux of $850 \mathrm{hPa}$ found in observations (Peixoto and Oort 1992) and the height of maximum vertical mass flux and condensation of $825 \mathrm{hPa}$ found in an idealized 

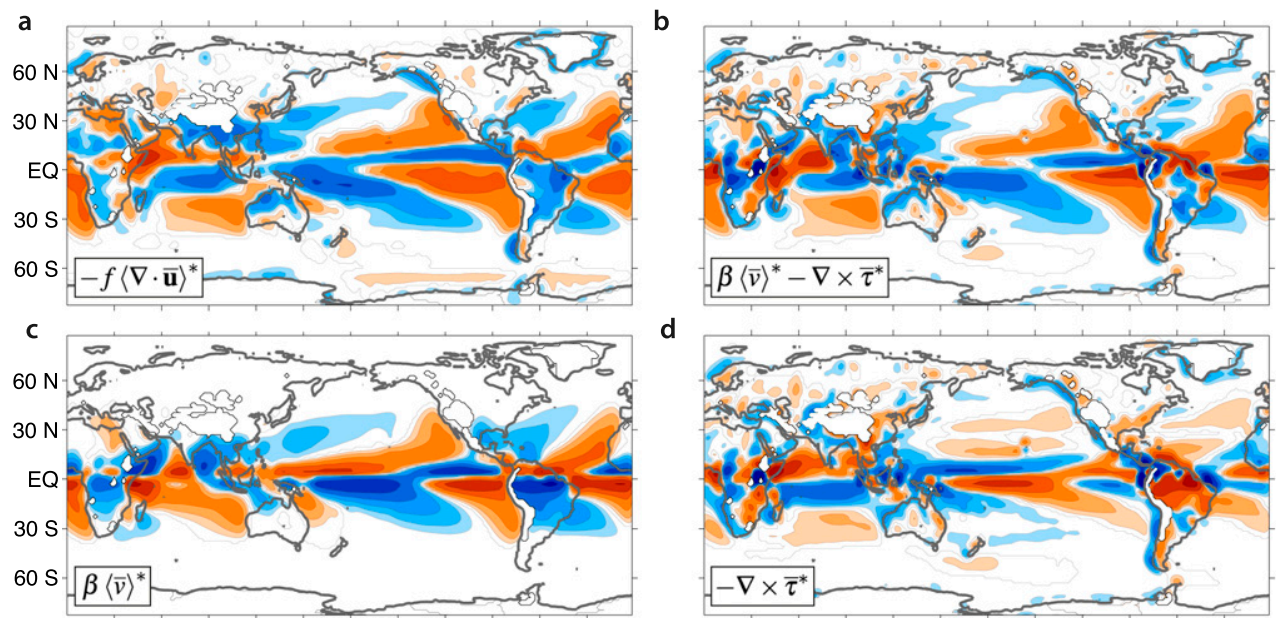

d
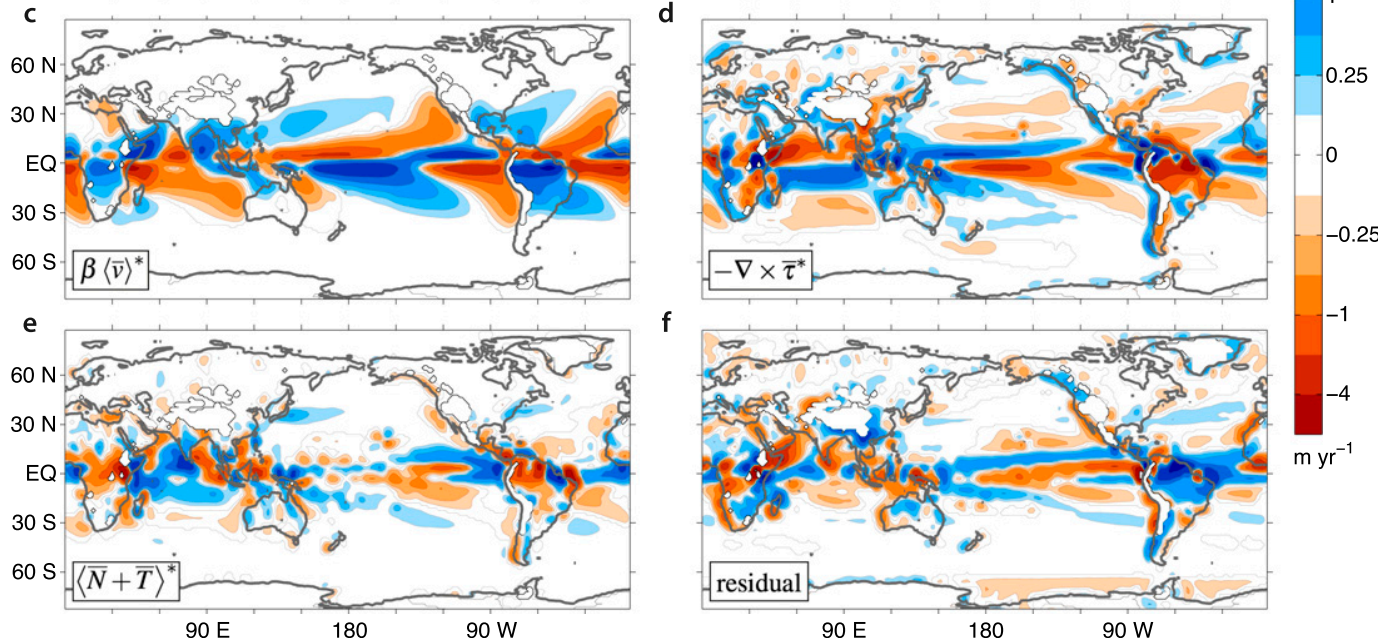

FIG. 8. Dominant terms of the zonally anomalous vertically integrated vorticity budget for ERA-Interim (from surface to $850 \mathrm{hPa}$ ) multiplied by $\left[\bar{q}_{\mathrm{sfc}}\right] / f$ such that the planetary vorticity stretching term gives the approximate stationary-eddy divergence contribution to $\bar{P}^{*}-\bar{E}^{*}$. (a) Planetary vorticity component of stretching term. (b) Sum of beta term and surface drag. (c) Beta term. (d) Surface drag. (e) All nonlinear terms involving transient and stationary eddies. (f) Residual of all calculated vorticity tendencies, $-\langle f \nabla \cdot \overline{\mathbf{u}}+\beta \bar{v}+\bar{N}+\bar{T}\rangle^{*}+\nabla \times \bar{\tau}^{*}$, which can be interpreted as an artificial forcing by the reanalysis. As $f \rightarrow 0$ at the equator, the equatorial grid points are omitted for all fields, and contouring interpolates between the next-nearest grid points across the equator. The limits of integration, from $850 \mathrm{hPa}$ to $\bar{p}_{s}$, are omitted from the figure labels. No data are plotted where $\bar{p}_{s}$ is less than $850 \mathrm{hPa}$.

model (Schneider et al. 2010). The main spatial variability in the best fit $p_{i}$ comes from the difference between land and ocean. The global mean best fit $p_{i}$ values for land and ocean are 825 and $875 \mathrm{hPa}$ respectively. This difference is not large enough to necessitate using different values for land and ocean.

Thus, in the modern climate, $\bar{P}^{*}-\bar{E}^{*}$ can be thought of as a product of boundary layer specific humidity and zonally anomalous vertical motion at $850 \mathrm{hPa}, \bar{\omega}_{850}^{*} \approx g\left(\langle\nabla \cdot \overline{\mathbf{u}}\rangle_{850}^{\bar{p}_{s}}\right)^{*}$ :

$$
\bar{P}^{*}-\bar{E}^{*} \approx-\frac{1}{g}\left[\bar{q}_{\mathrm{sfc}}\right] \bar{\omega}_{850}^{*} .
$$

This approximation is qualitative due to the neglect of transient eddies and horizontal advection, which also contribute to $\bar{P}^{*}-\bar{E}^{*}$. The level at which vertical motion contributes most to $P-E$ is likely to change with climate as the center of mass of moisture and condensation moves up in the atmosphere (O'Gorman and Schneider 2008; Singh and O'Gorman 2012). This will be the subject of future study.
To study the physical balances leading to vertical motion at $850 \mathrm{hPa}$, we will analyze the steady-state vorticity equation integrated from the surface upward. The zonally anomalous component below a level $p_{i}$ can be written as

$$
\left(\langle f \nabla \cdot \overline{\mathbf{u}}+\beta \bar{v}+\bar{N}+\bar{T}\rangle_{p_{i}}^{\bar{p}_{s}}\right)^{*}=\nabla \times \bar{\tau}^{*},
$$

where $f$ is the Coriolis frequency, $\beta=d f / d y, \tau$ is the surface stress due to turbulent momentum fluxes, $N$ represents all nonlinear interactions within the time mean flow (e.g., relative vorticity fluxes), given by

$$
\bar{N}=\overline{\mathbf{v}} \cdot \nabla \bar{\zeta}+\bar{\zeta} \nabla \cdot \overline{\mathbf{u}}+\left(\nabla_{x} \cdot \bar{\omega}\right) \partial_{p} \bar{v}-\left(\nabla_{y} \cdot \bar{\omega}\right) \partial_{p} \bar{u},
$$

and $T$ represents the total transient-eddy vorticity tendency, given by

$$
\bar{T}=\overline{\mathbf{v}^{\prime} \cdot \nabla \zeta^{\prime}}+\overline{\zeta^{\prime} \nabla \cdot \mathbf{u}^{\prime}}+\overline{\left(\nabla_{x} \cdot \omega^{\prime}\right) \partial_{p} v^{\prime}}-\overline{\left(\nabla_{y} \cdot \omega^{\prime}\right) \partial_{p} u^{\prime}} .
$$

Here $\zeta$ is the relative vorticity and $\mathbf{v}=(u, v, \omega)$ is the full 3D velocity. Figure 8 shows the terms in the 
stationary-eddy vorticity equation in ERA-Interim. Each field is multiplied by $\left[\bar{q}_{\text {sfc }}\right] / f$ such that it shows the contribution of the corresponding vorticity budget term to $\bar{P}^{*}-\bar{E}^{*}$ via time-mean vertical motion, as for example,

$$
\frac{\left[\bar{q}_{\mathrm{sfc}}\right]}{f}\left(\langle f \nabla \cdot \overline{\mathbf{u}}\rangle_{p_{i}}^{\bar{p}_{s}}\right)^{*} \approx\langle[\bar{q}] \nabla \cdot \overline{\mathbf{u}}\rangle^{*} .
$$

Stationary eddies have two dominant influences on zonal variation in $850-\mathrm{hPa}$ vertical motion. The first is Sverdrup balance,

$$
-f\left(\langle\nabla \cdot \overline{\mathbf{u}}\rangle_{p_{i}}^{\bar{p}_{s}}\right)^{*} \sim \beta\left(\langle\overline{\boldsymbol{v}}\rangle_{p_{i}}^{\bar{p}_{s}}\right)^{*},
$$

where stretching of absolute vorticity $\left(-f \nabla \cdot \overline{\mathbf{u}}^{*}\right)$ is balanced by planetary vorticity advection $\left(\beta \bar{v}^{*}\right)$, such that regions of poleward motion are wetter than the zonal mean (Fig. 8c). The second is Ekman pumping,

$$
-f\left(\langle\nabla \cdot \overline{\mathbf{u}}\rangle_{p_{i}}^{\bar{p}_{s}}\right)^{*} \sim-\nabla \times \bar{\tau}^{*},
$$

here taken to mean the balance of absolute vorticity stretching by surface drag (in a slight deviation from common terminology), such that regions with stationary-eddy cyclones are wetter than the zonal mean (Fig. 8d). Figure 8b shows the sum of the effects of Sverdrup balance and Ekman pumping. Together, they show the primary large-scale patterns of stationary-eddy vertical motion, and, through the moisture budget balances discussed in section $3, \bar{P}^{*}-\bar{E}^{*}$. This can be represented by the qualitative scaling

$$
\bar{P}^{*}-\bar{E}^{*} \approx \frac{\left[\bar{q}_{\mathrm{sfc}}\right]}{f}\left(\langle\beta \bar{v}\rangle_{850}^{\overline{p_{s}}}-\nabla \times \bar{\tau}\right)^{*} .
$$

The net moisture-weighted vorticity tendency due to all nonlinear terms (Fig. 8e) acts mostly on smaller length scales in the tropics. This is the sum of vorticity advection, nonlinear vorticity stretching, vortex tilting, and baroclinicity. Baroclinicity enters the vorticity equation in pressure coordinates through fluctuations in surface pressure, and is thus classified as a transient eddy in our framework. The only large-scale cancelation internal to these terms is the $\sim 1 \mathrm{~m} \mathrm{yr}^{-1}$ moisture-weighted export of vorticity from the Walker circulation upwelling regions to the Walker circulation subsidence regions by $\bar{N}^{*}$ (not shown), and the cancellation of this tendency by horizontal transient-eddy vorticity advection.

The reanalysis framework does not guarantee a closed vorticity budget. The net effect of the vorticity budget residual is shown in Fig. 8f. While significant, especially over the Pacific and over South America, it does not qualitatively change the balances on large scales that we have described. Overall, a significant portion of large-scale
$\bar{P}^{*}-\bar{E}^{*}$ variability in the modern climate is seen to occur through lower-tropospheric stationary-eddy vertical motion associated with a combination of Sverdrup balance and Ekman pumping.

\section{Implications for sea surface salinity}

Spatial variability of $P-E$ is a major control on the spatial variability of the surface salinity of the oceans (W83; Broecker et al. 1985; Zaucker et al. 1994; Delcroix et al. 1996; EG03; De Boer et al. 2008; Czaja 2009; Ferreira et al. 2010; Nilsson et al. 2013). Transport of water by the ocean, sea ice, and rivers are the remaining mechanisms that can lead to spatial variability in freshwater forcing and sea surface salinity (SSS). The zonal variation of $\bar{P}-\bar{E}$ is thus an important control on the SSS difference between the Pacific and Atlantic Oceans. W83 and EG03 have focused, in particular, on the moisture budget influence on the freshwater forcing of the North Pacific (NP) and North Atlantic (NA) subpolar gyres, where the NA surface water is saltier over a range of latitudes (Figs. 9b,c) due in part to the lower $P-E$ freshwater forcing in the NA in these latitudes (Figs. 9d,e). This is motivated by the suggestion that the high-latitude surface-deep salinity difference controls the strength of deep ocean overturning (W83; Broecker et al. 1985).

Simulations with coupled atmosphere-ocean models (Ferreira et al. 2010; Nilsson et al. 2013) have shown that a difference in $\bar{P}-\bar{E}$ between two idealized ocean basins, due to, in their case, differing ocean basin width, is enough to restrict deep ocean overturning to the drier ocean basin. In addition to the influence of $\bar{P}-\bar{E}$, the Pacific-Atlantic salinity difference is also thought to be influenced by interbasin Sverdrup salt transport due to the differing extents of South America and Africa (Reid 1953; Nilsson et al. 2013), regional details of the ocean basins (e.g., the Mediterranean Sea, the Arctic throughflow, and the farther northward extent of the Atlantic) (Reid 1979; Weaver et al. 1999; De Boer et al. 2008), and differences in the zero wind stress curl line, which sets the boundary and mixing between the subtropical and subpolar gyres (W83; EG03; Czaja 2009). We will focus on the $\bar{P}-\bar{E}$ freshwater forcing aspect of the problem as it is well established to play a large role, and the moisture budget decomposition of section 3 has the potential to elucidate mechanisms for ocean basin $\bar{P}-\bar{E}$ differences.

EG03 give an overview of contributions to the modern NP salinity budget in comparison with the modern NA, using observational estimates of $P-E$, runoff, salt fluxes, and ocean currents, an update of previous work by W83. We provide updated $P-E$ fluxes from ERA-Interim and 

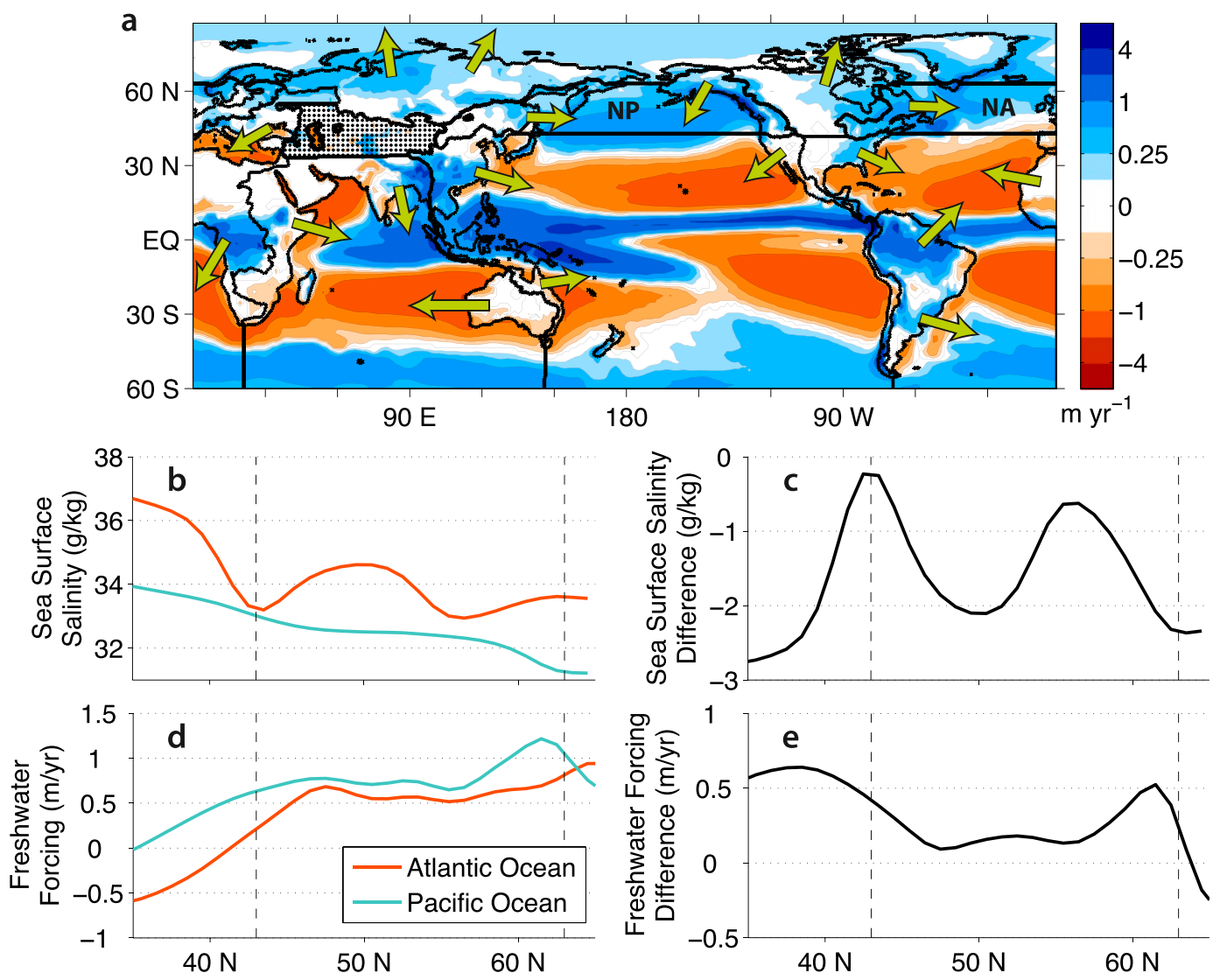

FIG. 9. (a) Total $\bar{P}-\bar{E}$ and outline of ocean boxes and their catchment basins computed from the STN-30p river topology dataset. The ocean is split into Pacific, Atlantic, and Indian Oceans as shown, as well as a North Pacific (NP) and North Atlantic (NA) box as used in Tables 3 and 4. Endoheric basins are stippled. (b) Ocean basin zonal-mean sea surface salinity from the World Ocean Atlas (Zweng et al. 2013) in the North Pacific and North Atlantic basins and (c) Pacific-Atlantic difference. (d) Ocean basin zonal-mean freshwater forcing into the North Pacific and North Atlantic and (e) Pacific-Atlantic difference.

MERRA, decomposing the total freshwater flux into components due to stationary-eddy vertical motion, transient eddies, other stationary-eddy moisture flux terms, and differences in river runoff topology. We approximate the NP and NA subpolar gyres by a box between $43^{\circ}$ and $63^{\circ} \mathrm{N}$ as shown in Fig. 9a. This follows EG03 except for an expansion of the northern boundary from $60^{\circ}$ to $63^{\circ} \mathrm{N}$, consistent with the inclusion of the Yukon River (as in EG03). The freshwater flux contributions from the different components of the moisture budget as in Eqs. (7) and (9) are tabulated in Table 3 (in $\mathrm{mSv} ; 1 \mathrm{mSv}=10^{3} \mathrm{~m}^{3} \mathrm{~s}^{-1}$ ).

We use the STN-30p river topology dataset (Fekete et al. 2001; Vörösmarty et al. 2000) to route net precipitation that falls over land into the appropriate ocean basin. The boundaries of the catchments for each ocean basin are shown in Fig. 9a. These boundaries compare well to higher-resolution estimates (e.g., Lehner et al. 2008), except for the lack of several major endoheric basins (basins with no outflow to the oceans) such as the Artesian Basin in Australia, the Great Basin in the United States, and the large endoheric region of the Sahara desert. Since these are all regions where $P-E \approx 0$, far from the subpolar gyres, this should not affect our analysis. Dai and Trenberth (2002) use the same river runoff routing dataset with ERA-40 $P-E$ forcing and find it to be comparable to estimates derived from datasets of river runoff, as used in EG03. The influence of runoff to the total freshwater forcing of the NP and NA is included in Table 3.

Since we use approximately the same NP and NA boxes as EG03, the values in Table 3 for total $\bar{P}-\bar{E}$ and for $\bar{P}$ and $\bar{E}$ are directly comparable with the values in EG03. For $\bar{P}-\bar{E}$, the ERA-Interim and MERRA values agree well with each other and are well within EG03's published uncertainty range (Table 3). The runoff estimates, corresponding to on-land $P-E$, are more spread within the datasets and do not lie within EG03's 
TABLE 3. Freshwater forcing $(\mathrm{mSv})$ to the oceans between $43^{\circ}$ and $63^{\circ} \mathrm{N}$. ERA-Interim and MERRA (in parentheses) are both shown. Values in brackets are from EG03.

\begin{tabular}{|c|c|c|c|c|}
\hline & $\begin{array}{l}\text { Pacific } \\
P-E\end{array}$ & $\begin{array}{l}\text { Pacific } \\
\text { runoff }\end{array}$ & $\begin{array}{c}\text { Atlantic } \\
P-E\end{array}$ & $\begin{array}{l}\text { Atlantic } \\
\text { runoff }\end{array}$ \\
\hline \multirow[t]{2}{*}{$\bar{P}-\bar{E}$} & $213(210)$ & $70(54)$ & $103(110)$ & $64(40)$ \\
\hline & {$[290 \pm 150]$} & {$[30 \pm 3]$} & {$[170]$} & \\
\hline \multirow[t]{2}{*}{$\bar{P}$} & $417(394)$ & 140 (139) & $340(326)$ & $148(142)$ \\
\hline & {$[450 \pm 150]$} & & {$[350]$} & \\
\hline \multirow[t]{2}{*}{$\bar{E}$} & $204(185)$ & $70(86)$ & $237(216)$ & 85 (102) \\
\hline & {$[180 \pm 36]$} & & {$[180 \pm 36]$} & \\
\hline$\overline{[P]}-\overline{[E]}$ & 115 (99) & $56(46)$ & $93(78)$ & $52(45)$ \\
\hline $\bar{P}^{*}-\bar{L}^{*}$ & $98(113)$ & $14(6.3)$ & $10(30)$ & $11(-3.7)$ \\
\hline$-\left\langle\nabla \cdot\left(\overline{\mathbf{u}}^{\dagger} \bar{q}^{\dagger}\right)\right\rangle^{*}$ & $61(60)$ & $-14(-22)$ & $30(29)$ & $-22(-25)$ \\
\hline$-\left\langle\nabla_{y} \cdot([\overline{\mathbf{u}}][\bar{q}])\right\rangle^{*}$ & $2.7(4.0)$ & $-3.0(-3.5)$ & $3.6(4.5)$ & $0.3(0.4)$ \\
\hline$-\left\langle\nabla \cdot \overline{\mathbf{u}^{\prime} q^{\prime}}\right\rangle^{*}$ & $53(51)$ & $8.1(9.4)$ & $-15(-12)$ & $23(19)$ \\
\hline$-\langle[\bar{q}] \nabla \cdot \overline{\mathbf{u}}\rangle *$ & $46(31)$ & $5.1(6.4)$ & $12(7.2)$ & $-12(-14)$ \\
\hline$-\left\langle\bar{q}^{*} \nabla \cdot \overline{\mathbf{u}}\right\rangle^{*}$ & $-0.8(0.8)$ & $-0.4(-0.8)$ & $2.5(2.6)$ & $-1.0(-0.3)$ \\
\hline$-\langle\overline{\mathbf{u}} \cdot \nabla \bar{q}\rangle^{*}$ & $22(37)$ & $-17(-22)$ & $18(24)$ & $-9.9(-10)$ \\
\hline$-\bar{S}^{*}$ & $-19(-2.3)$ & $23(22)$ & $-7.6(9.1)$ & $9.8(1.5)$ \\
\hline
\end{tabular}

uncertainty range for the NP. However, EG03 only included the 11 biggest rivers contributing to this box and made no attempt to extrapolate downstream from the farthest downstream gauging station. Dai and Trenberth (2002) show that this extrapolation increases runoff globally by $19 \%$. In particular, for the Columbia River, a key contributor to the NP box, they find that ignoring this downstream extrapolation underestimates the discharge to the ocean by approximately $3 \mathrm{mSv}$. Therefore, the values in Table 3 are within reason and can likely be trusted for the following primarily qualitative arguments.

The net freshwater flux into the Pacific is increased relative to the Atlantic simply because of the larger area of the Pacific. For this reason, it is convenient in many contexts to look instead at the net freshwater flux per area, tabulated in Table 4 (in $\mathrm{cm} \mathrm{yr}^{-1}$ ), which differs from Table 3 only by a factor of ocean area. The average runoff, shown in Table 4 for each ocean basin, is equivalent to spreading the runoff over the full area of the ocean basin. The NP and NA freshwater forcing terms in Table 4 are thus area independent and provide the best comparison between the ocean basins for each term.

As in W83 and EG03, we find that the difference in $\bar{P}-\bar{E}$ between the high-latitude oceans takes the form of a difference in $\bar{E}$ as opposed to a difference in $\bar{P}$. This is at least partially due to the ocean-atmosphere feedback discussed by W83 and Broecker et al. (1985), where deep convection in the NA causes more northward transport of warm ocean waters, which increases evaporation over the NA, reinforcing oceanic deep convection and the overturning circulation. Czaja (2009) argues that looking at the freshwater budget is thus circular because the evaporation reflects the state of the overturning circulation in the ocean basin. But without a difference in atmospheric circulation, a higher $\bar{E}$ would lead to a higher $\bar{P}$ and thus to no difference in freshwater

TABLE 4. Average freshwater forcing $\left(\mathrm{cm} \mathrm{yr}^{-1}\right)$ to the oceans between $43^{\circ}$ and $63^{\circ} \mathrm{N}$. ERA-Interim and MERRA (in parentheses) are both shown.

\begin{tabular}{ccccc}
\hline \hline & $\begin{array}{c}\text { Pacific } \\
P-E\end{array}$ & $\begin{array}{c}\text { Pacific } \\
\text { runoff }\end{array}$ & $\begin{array}{c}\text { Atlantic } \\
P-E\end{array}$ & $\begin{array}{c}\text { Atlantic } \\
\text { runoff }\end{array}$ \\
\hline $\bar{P}-\bar{E}$ & $55(54)$ & $18(14)$ & $32(34)$ & $19(12)$ \\
$\bar{P}$ & $108(102)$ & $36(36)$ & $104(100)$ & $75(44)$ \\
$\bar{E}$ & $53(48)$ & $18(22)$ & $75(66)$ & $27(31)$ \\
$\overline{[P]}-\overline{[E]}$ & $30(26)$ & $14(12)$ & $28(24)$ & $16(14)$ \\
$\bar{P}^{*}-\bar{E}^{*}$ & $25(29)$ & $3.6(1.9)$ & $3.2(9.7)$ & $3.4(-1.6)$ \\
$-\left\langle\nabla \cdot\left(\overline{\mathbf{u}}^{\dagger} \bar{q}^{\dagger}\right)\right\rangle^{*}$ & $16(16)$ & $-3.5(-5.6)$ & $9.1(8.9)$ & $-6.8(-7.6)$ \\
$-\left\langle\nabla_{y} \cdot([\overline{\mathbf{u}}][\bar{q}])\right\rangle^{*}$ & $0.7(1.0)$ & $-0.8(-0.9)$ & $-4.7(-3)$ & $7.4(0.1)$ \\
$-\left\langle\nabla \cdot \overline{\mathbf{u}}^{\prime} q^{\prime}\right\rangle^{*}$ & $14(13)$ & $2.1(2.4)$ & $3.8(2.2)$ & $-3.2(5.9)$ \\
$-\langle[\bar{q}] \boldsymbol{\nabla} \cdot \overline{\mathbf{u}}\rangle^{*}$ & $12(8.1)$ & $1.3(1.7)$ & $0.8(1.4)$ & $-0.3(-1.2)$ \\
$-\left\langle\bar{q}^{*} \nabla \cdot \overline{\mathbf{u}}\right\rangle^{*}$ & $-0.2(0.2)$ & $-0.1(-0.2)$ & $5.7(7.3)$ & $-3.1(-3.1)$ \\
$-\langle\overline{\mathbf{u}} \cdot \nabla \bar{q}\rangle^{*}$ & $5.7(9.5)$ & $-4.4(-5.7)$ & $-2.3(2.8)$ & $3.0(0.5)$ \\
$-\bar{S}$ & $-4.9(-0.6)$ & $5.8(5.7)$ & &
\end{tabular}


forcing. So, since the relevant quantity for SSS is $\bar{P}-\bar{E}$, the question becomes this: How is $\bar{P}$ as large over the NP despite the lower $\bar{E}$ ? This is a question of moisture transport that motivates studying the moisture budget decomposition that makes up the rest of Tables 3 and 4 .

The stationary-eddy vertical motion term, $-\langle[\bar{q}] \nabla \cdot \overline{\mathbf{u}}\rangle^{*}$, is a dominant term, freshening the NP with respect to the NA by $13 \mathrm{~cm} \mathrm{yr}^{-1}$ (ERA-Interim) on average (including its influence on runoff), consistent with its dominant role in the moisture budget as shown in section 3. The vertical motion over the NP results primarily from poleward motion (Sverdrup balance) and surface stress (Ekman pumping) associated with the Aleutian low and Pacific subtropical high. Transient-eddy moisture fluxes also act to freshen the NP with respect to the NA by $14 \mathrm{~cm} \mathrm{yr}^{-1}$ on average, consistent with the mechanism discussed by Ferreira et al. (2010), according to which the North Atlantic storm track has less fetch in which to develop and is weaker as a result, with some moisture transported out of the Atlantic and into continental Asia. Note from Fig. 3 that these high-latitude ocean boxes are among the only ocean areas where transient-eddy moisture flux convergence dominates the contribution of stationary-eddy vertical motion. Other stationary eddy terms, such as the time-mean horizontal moisture advection, $-\langle\overline{\mathbf{u}} \cdot \nabla \bar{q}\rangle^{*}$, also play significant roles in the freshwater forcing of the Northern Hemisphere subpolar gyres, but are not significantly different between the NP and NA. The surface term, $-\bar{S}^{*}$, is the largest contributor to the runoff forcing of the subpolar gyres but does not lead to as much total freshwater forcing as the stationary and transient eddy terms. The combination of all of these terms makes the total contribution of $\bar{P}^{*}-\bar{E}^{*}$ to the NP-NA freshwater forcing difference a net freshening of the NP by $22 \mathrm{~cm} \mathrm{yr}^{-1}$.

Somewhat counterintuitively, the zonal mean $\overline{[P]}-\overline{[E]}$ can also influence the difference in freshwater forcing simply through the different latitudinal distribution of area of the NP and NA and through ocean basin differences in river routing. The NP has a larger percentage of its area in wetter latitude bands than the NA, leading to a larger direct contribution from $\overline{[P]}-\overline{[E]}$, while the NA has a larger catchment area to surface area ratio, $D_{\mathrm{NA}} / A_{\mathrm{NA}}=0.57$, than the NP, $D_{\mathrm{NP}} / A_{\mathrm{NP}}=0.48$, leading to a larger runoff contribution from $\overline{[P]}-\overline{[E]}$. These effects cancel such that the total $\bar{P}-\bar{E}$ freshwater forcing difference between the NP and NA is just due to $\bar{P}^{*}-\bar{E}^{*}$.

We can get a rough sense of the contribution of these effects to the NP salinity $\left(\mathcal{S}_{\mathrm{NP}}\right)$ using the simple box model for NP salinity from EG03:

$$
\overline{\mathcal{S}}_{\mathrm{NP}}=\frac{\bar{F}_{s}}{\bar{V}+\bar{P}-\bar{E}+\bar{R}} .
$$

Here $\bar{F}_{s}$ is the total salt flux convergence, $\bar{V}$ is oceanic volume throughflow, and $\bar{R}$ is river runoff. W83 and EG03 have explored the dependencies of this box model, finding that a combination of the high local $\bar{P}-\bar{E}$ and the low throughflow current $\bar{V}$, which increases the sensitivity to changes in the other terms, reduces the salinity of the NP, with a contribution from the low salt flux convergence $\bar{F}_{s}$ owing to the freshness of the Pacific equatorward of the subpolar gyre.

Using the values $\overline{F_{s}}=200 \times 10^{6} \mathrm{~kg} \mathrm{~s}^{-1}$ and $\bar{V}=5.76 \times$ $10^{9} \mathrm{~kg} \mathrm{~s}^{-1}$, from EG03, and $\bar{P}-\bar{E}=213 \mathrm{mSv}$ and $\bar{R}=$ $70 \mathrm{mSv}$, according to Table 3 , we obtain $\overline{\mathcal{S}}_{\mathrm{NP}}=33.1 \%$. This is comparable to the similar calculation in EG03, which obtained $32.9 \%$, and to an observational average of the upper $200 \mathrm{~m}$ of the NP box, obtaining $32.9 \%$. Substituting the Atlantic values of $\bar{P}-\bar{E}(103 \mathrm{mSv})$ and $\bar{R}(64 \mathrm{mSv})$ from Table $3, \overline{\mathcal{S}}_{\mathrm{NP}}$ increases to $33.7 \%$. Combined with an increased $\overline{F_{S}}=204 \times 10^{6} \mathrm{~kg} \mathrm{~s}^{-1}$ corresponding to a $2 \%$ increase in the western boundary current salinity as in EG03, we obtain an Atlantic-like $\overline{\mathcal{S}}_{\mathrm{NP}}=34.4 \%$, exceeding the observational average salinity below $200 \mathrm{~m}$ of $34.3 \%$ and thus potentially allowing intermediate-to-deep convection. For comparison, the average salinity of the NA over the upper $200 \mathrm{~m}$ is $34.1 \%$. All observational salinity data are averaged from the World Ocean Atlas (Zweng et al. 2013).

This analysis suggests that the NP-NA salinity difference comes from a combination of local differences in $\bar{P}-\bar{E}$ and river input and the difference in the salinity of the western boundary currents, which can be attributed to $\bar{P}-\bar{E}$ differences in the subtropics or ocean circulation mechanisms such as the interbasin Sverdrup salt balance proposed by Reid (1953) and illustrated by the experiments of Nilsson et al. (2013). The local $\bar{P}-\bar{E}$ differences arise from differences in vertical motion associated with the Aleutian low and subtropical highs as well as differences in transient eddy activity between the ocean basins. The subtropical Pacific-Atlantic $\bar{P}-\bar{E}$ differences are almost entirely due to differences in vertical motion between the ocean basins. However, this is not inconsistent with the importance of zonal moisture transport across Central America as discussed by W83, Zaucker et al. (1994), EG03, and others, as the convergence of this easterly moisture flux would lead to a contribution to the vertical moisture flux term.

\section{Discussion and conclusions}

We have shown that much zonal variation in $P-E$ is linked to lower-tropospheric vertical motion in stationary eddies. This stationary-eddy vertical motion explains planetary-scale patterns such as the Pacific warm pool, the zonal variability of the ITCZ, subtropical dry zones in the 
eastern ocean basins, and $\bar{P}-\bar{E}$ patterns in some land areas such as inland South America, western Africa, western Australia, and Canada. Transient eddies are also an important component of the zonally anomalous hydrological cycle, primarily acting to bring moisture onto land and across the Northern Hemisphere storm tracks. This is particularly important in coastal land areas that would otherwise be dried by stationary wave subsidence (e.g., western North America, northern China, and Chile). Horizontal advection of moisture by the time-mean flow largely cancels with transient eddy fluxes and does not play a dominant role. These conclusions can be extended to the full moisture budget including zonal mean components (see appendix B).

Overall, the majority of spatial variability in $\bar{P}^{*}-\bar{E}^{*}$ is explained by regional differences in vertical motion, not moisture content. This highlights the need to study the response of zonally anomalous circulations to climate change, to understand the potential for regional changes in hydroclimate. In midlatitudes, this would primarily entail the study of stationary Rossby waves, and their interaction with transient Rossby waves. In models, stationary Rossby waves are sensitive to the latitudinal structure of the zonal wind and to the relative location of the zonal wind to topography and heating (Hoskins and Karoly 1981). It is thus essential to know the exact response of the zonal wind to climate change in order to know how regional hydroclimate will respond to climate change. In the tropics and subtropics, zonally anomalous circulations take the form of zonal variation of the ITCZ position and the monsoon response to topography and heating, and it is thus essential to understand how these systems respond to climate change.

In some regions, zonally anomalous vertical motion is a direct response to high sea surface temperatures (SSTs) and the resulting evaporation and deep convection (e.g., the warm pool) or to subsidence downstream from topography (e.g., directly off the west coast of South America). In others, the vertical motion is forced remotely by stationary Rossby waves and other stationaryeddy circulations (e.g., the dry zone off the coast of California, the wet zone extending across the North $\mathrm{Pa}$ cific, and the extension of the dry zone off the west coast of South America into the central Pacific). Other studies have gone into more detail on the mechanisms in these particular regions (Rodwell and Hoskins 1996, 2001; Takahashi and Battisti 2007). In still other regions, such as the South Pacific convergence zone and the Gulf of Mexico, there is likely a more complex interaction between remotely forced vertical motion and that forced by local high SSTs.

To address the large-scale balances relating vertical motion to horizontal flow, we have performed a vorticity budget analysis for anomalies from the zonal mean in the lower troposphere (below $850 \mathrm{hPa}$ ). Within stationaryeddy circulations, lower-level vertical motion is associated with Sverdrup balance and Ekman pumping on large scales. Through these balances, vertical motion can arise from meridional motion and surface stress curls such that poleward (equatorward) motion or cyclonic (anticyclonic) circulations are linked to upward (downward) motion and wet (dry) regions.

Because SSS reflects the long-term $\bar{P}-\bar{E}$ freshwater forcing of a region, the moisture budget decomposition discussed here can be applied to understand regional differences in SSS. The subpolar oceans in the Northern Hemisphere are an interesting example because the ocean basin asymmetry in ocean freshwater forcing and SSS contribute to the asymmetry in deep overturning of the ocean, which is localized to the North Atlantic. Our analysis suggests that changes in SSS and ocean overturning in past climates likely can be understood in terms of changes in the water vapor content at high latitudes (i.e., $[\bar{q}])$, the large-scale vertical motion patterns $\left(\bar{\omega}^{*}\right)$, and transient-eddy moisture fluxes. The water vapor content $[\bar{q}]$ is primarily governed by thermodynamics. Stationaryeddy vertical motion $\bar{\omega}^{*}$ would respond to changes in topography (ice sheets), changes in ocean heat release, and shifts in the jet stream. Transient-eddy moisture fluxes are influenced by the meridional temperature gradient, atmospheric stability, and atmospheric moisture content (Caballero and Langen 2005; O'Gorman and Schneider 2008; Caballero and Hanley 2012).

Overall, the main conclusion of this study is that zonal variation in $P-E$ is strongly linked to the strength of zonally anomalous circulations, with less dependence on the zonal variation of moisture content. This can be applied to link the understanding of circulation dynamics to an understanding of the hydrological cycle.

Acknowledgments. This research has been supported by NSF Grant AGS-1019211. We thank Ori Adam for his work in developing the data portal GOAT (www. goat-geo.org), which was used to obtain the data for this study. We thank James Rae, Tobias Bischoff, and Momme Hell for useful comments and discussion during the development of this draft.

\section{APPENDIX A}

\section{Methods for Surface Intersections}

To satisfy conservation equations, it is important to density weight derivatives to ensure conservation of mass. This arises from using the continuity equation, 


$$
\partial_{t} \rho_{\eta}+\nabla_{\eta} \cdot\left(\rho_{\eta} \mathbf{v}\right)=0
$$

to convert a general conservation law for a field $\phi$ with a source $\Phi$ from advective form to flux form:

$$
\begin{gathered}
\partial_{t} \phi+\mathbf{v} \cdot \nabla \phi=\Phi \\
\rightarrow \frac{1}{\rho_{\eta}} \partial_{t}\left(\rho_{\eta} \phi\right)+\frac{1}{\rho_{\eta}} \nabla_{\eta} \cdot\left(\rho_{\eta} \mathbf{v} \phi\right)=\Phi,
\end{gathered}
$$

where $\nabla_{\eta}$ is the derivative on $\eta$-coordinate surfaces and $\rho_{\eta}=\rho\left(\partial_{z} \eta\right)^{-1}$ is the coordinate system density that satisfies

$$
\rho d x d y d z=\rho_{\eta} d x d y d \eta
$$

As such, derivatives must take account of the covariance of density $\rho_{\eta}$ and flux $\mathbf{v} \phi$. However, in pressure coordinates, $\rho_{p}$ is simply $\mathrm{H}_{\beta}\left(p-p_{s}\right) / g$, where $\mathrm{H}_{\beta}\left(p-p_{s}\right)$ is the Boer beta function (Boer 1982), a Heaviside function that sets the density to zero beneath the surface. This comes into play when computing derivatives as pressure levels cross the surface.

Writing out the density-weighting explicitly for the vertically integrated moisture flux divergence,

$$
\boldsymbol{\nabla} \cdot\langle\overline{\mathbf{u} q}\rangle=\left\langle\nabla \cdot \overline{\mathbf{u} q} \overline{\mathrm{H}}_{\beta}\right\rangle_{0}^{p_{0}},
$$

where $p_{0}$ is the maximum pressure level. Time averages are density weighted according to

$$
\overline{(\cdot)}=\int \rho_{\eta}(\cdot) d t / \int \rho_{\eta} d t
$$

Therefore, the time-average $\mathrm{H}_{\beta}$ can be separated from the time-average flux such that

$$
\boldsymbol{\nabla} \cdot\langle\overline{\mathbf{u} q}\rangle=\left\langle\nabla \cdot\left(\overline{\mathbf{u} q} \overline{\mathrm{H}}_{\beta}\right)\right\rangle_{0}^{p_{0}} .
$$

In this way, we can separate off a surface term due to the gradient of $\overline{\mathrm{H}}_{\beta}$,

$$
\begin{aligned}
\boldsymbol{\nabla} \cdot\langle\overline{\mathbf{u} q}\rangle & =\left\langle\overline{\mathrm{H}}_{\beta} \boldsymbol{\nabla} \cdot \overline{\mathbf{u} q}\right\rangle_{0}^{p_{0}}+\left\langle\overline{\mathbf{u} q} \cdot \nabla \overline{\mathrm{H}}_{\beta}\right\rangle_{0}^{p_{0}} \\
& =\langle\boldsymbol{\nabla} \cdot \overline{\mathbf{u} q}\rangle+\left.\overline{\mathbf{u} q}\right|_{\mathrm{sfc}} \cdot \nabla \bar{p}_{s} .
\end{aligned}
$$

We thus have an explicit formula for the surface term:

$$
\bar{S}=\left\langle\overline{\mathbf{u} q} \cdot \nabla \overline{\mathrm{H}}_{\beta}\right\rangle_{0}^{p_{0}}=\left.\overline{\mathbf{u} q}\right|_{\mathrm{sfc}} \cdot \nabla \bar{p}_{s} .
$$

While this expression gives a clear interpretation for the surface term as moisture fluxes along surface pressure gradients, it is better to calculate it from $\bar{S}=\nabla \cdot\langle\overline{\mathbf{u} q}\rangle-\langle\nabla \cdot \overline{\mathbf{u} q}\rangle$, which differs from Eq. (A8) by discretization issues.

As with time averages, zonal averages are density weighted according to

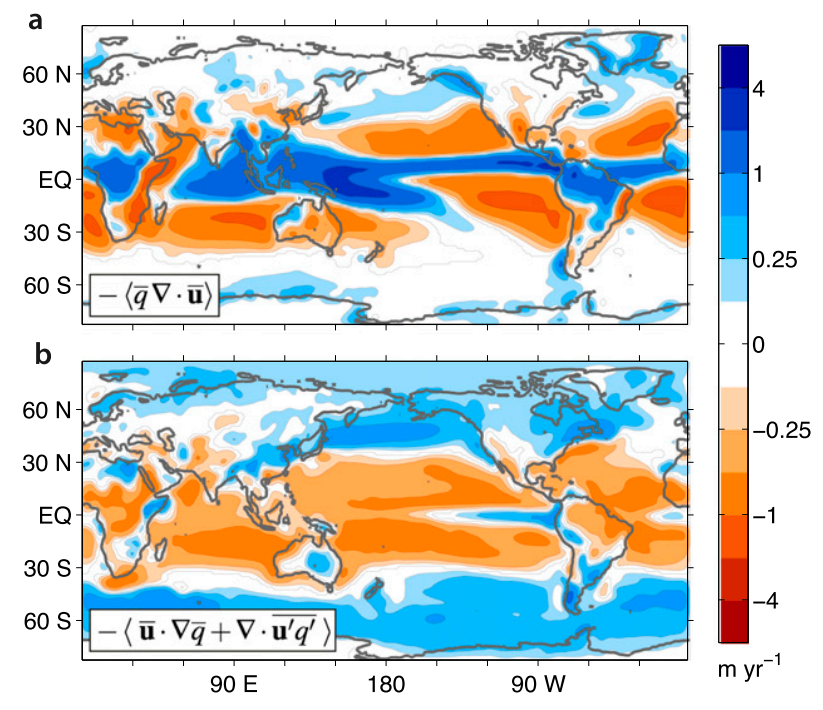

FIG. B1. Full (zonal-mean + zonally anomalous) moisture budget terms. (a) Time-mean mass divergence component of moisture budget, and (b) time-mean horizontal moisture advection combined with transient-eddy moisture flux convergence.

$$
[\cdot]=\int \rho_{\eta}(\cdot) d x / \int \rho_{\eta} d x,
$$

such that $\left[\overline{\mathrm{H}}_{\beta} \overline{\mathbf{u} q}\right]=\left[\overline{\mathrm{H}}_{\beta}\right][\overline{\mathbf{u} q}]$ as needed for Eq. (6).

\section{APPENDIX B}

\section{Application to the Full Moisture Budget}

Here we apply what we have learned from the zonally anomalous moisture budget to the full moisture budget including zonally anomalous and zonal mean components. As in the zonally anomalous moisture budget, mass convergence and vertical transport (Fig. B1a) set the predominant patterns of $\bar{P}-\bar{E}$ (Fig. 1) such as the ITCZ, Walker circulation, and subtropical dry zones. Here, the combined transient-eddy and time-mean horizontal advection term (Fig. B1b) plays a significant role. The transient eddies and horizontal transport provide a fairly uniform drying equatorward of $35^{\circ}$, and a fairly uniform moistening poleward of $35^{\circ}$, where this term is the dominant contribution to storm track precipitation.

The vorticity balance beneath $850 \mathrm{hPa}$ (Fig. B2) is still predominately Sverdrup balance and Ekman pumping. The descent leading to the subtropical dry zones is balanced by surface drag. The vorticity balance of the ITCZ is a more complex mixture of Sverdrup balance and Ekman pumping, with large cancelations between the beta term and surface drag 


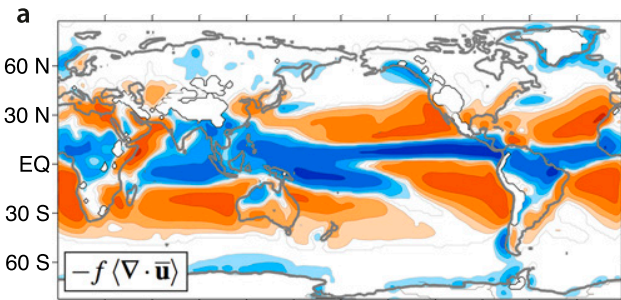

b
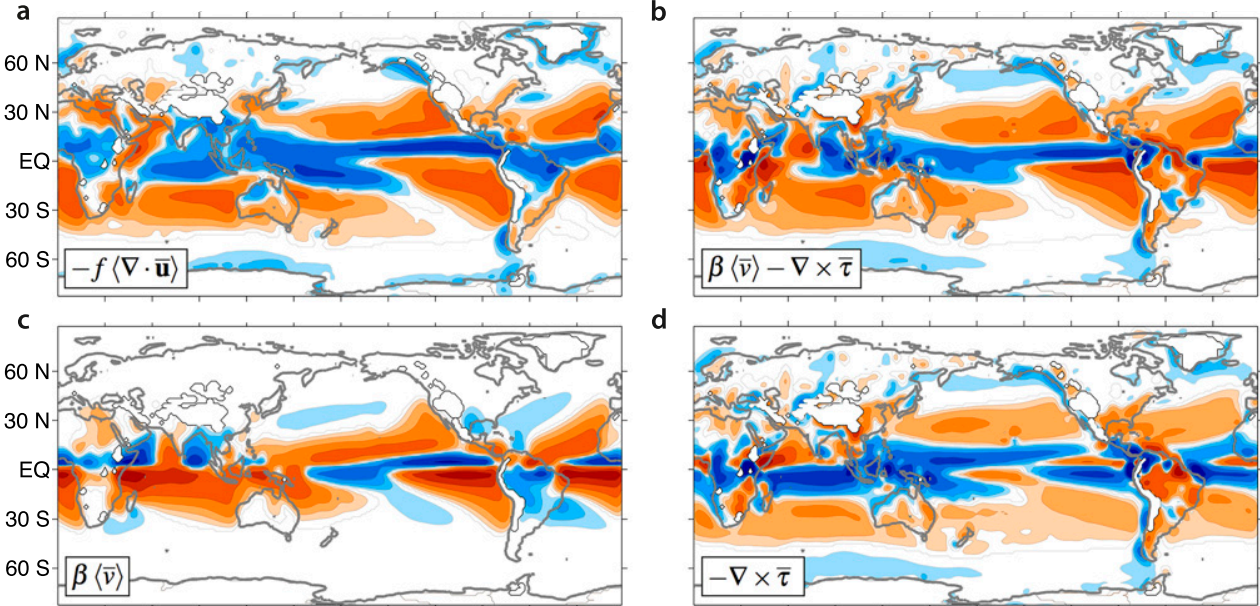

d
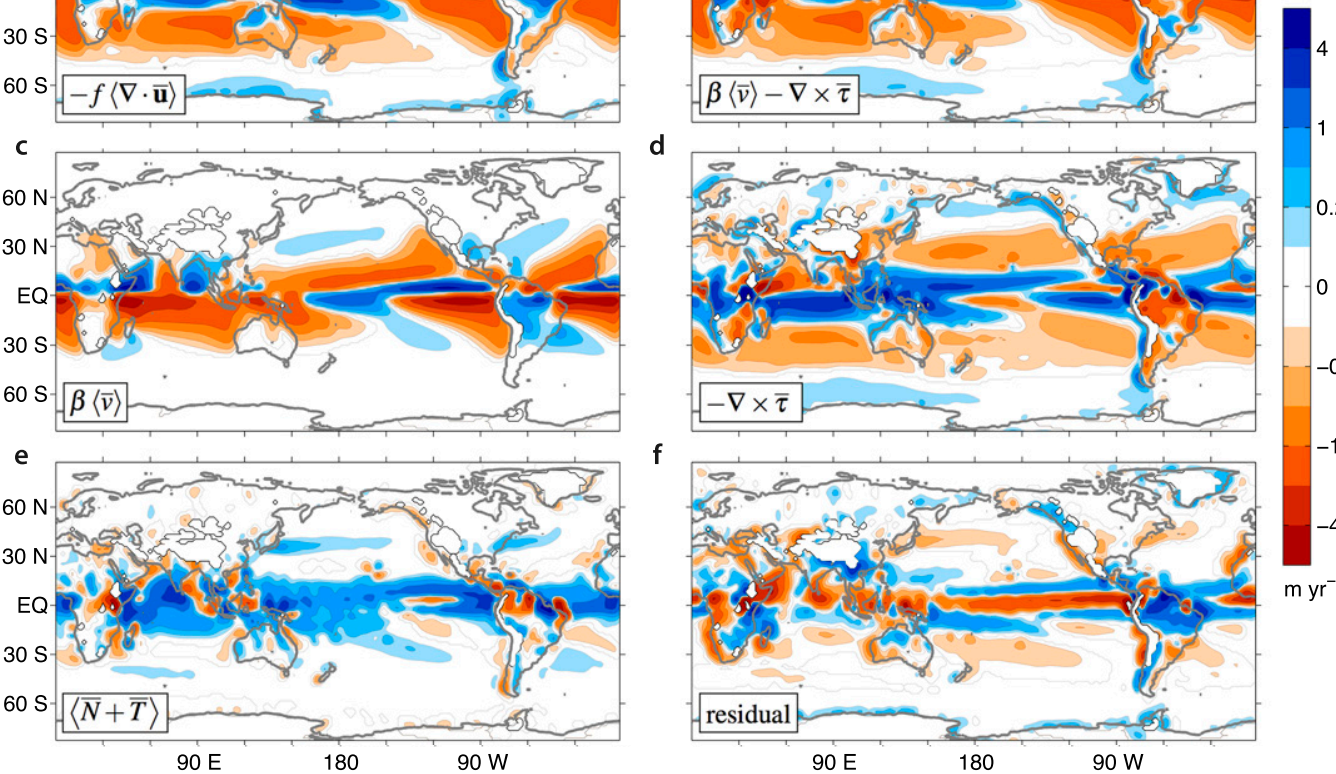

f

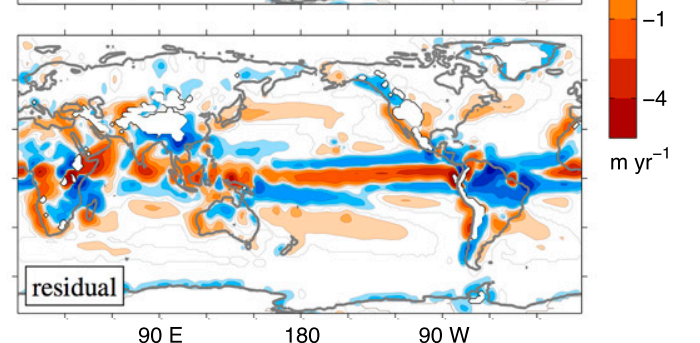

FIG. B2. Dominant terms of the total (zonal-mean and zonally anomalous) vertically integrated vorticity budget for ERA-Interim (from surface to $850 \mathrm{hPa}$ ) multiplied by $\left[\bar{q}_{\mathrm{sfc}}\right] / f$ such that the planetary vorticity stretching term gives the approximate flow divergence contribution to $\bar{P}-\bar{E}$. (a) Planetary vorticity component of stretching term. (b) Sum of beta term and surface drag. (c) Beta term. (d) Surface drag. (e) Nonlinear terms. (f) Residual of all calculated vorticity tendencies, $-\langle f \nabla \cdot \overline{\mathbf{u}}+\beta \bar{v}+\bar{N}+\bar{T}\rangle+\nabla \times \bar{\tau}$, which can be interpreted as an artificial forcing by the reanalysis. Treatment of equatorial grid points and limits of integration as in Fig. 8.

and a large residual in the reanalysis. The nonlinear terms play a more important role here than in the zonally anomalous budget, maintaining the vertical motion along much of the equator. This vertical motion is maintained through $\bar{T}$ in the warm pool and through $\bar{N}$ in the Walker cell subsidence region.

The mechanisms discussed in the main text apply particularly well for the zonal variation of the moisture budget, but also give insight into the full moisture budget.

\section{REFERENCES}

Betts, A. K., 1998: Climate-convection feedbacks: Some further issues. Climatic Change, 39, 35-38, doi:10.1023/A: 1005323805826.

Boer, G. J., 1982: Diagnostic equations in isobaric coordinates. Mon Wea. Rev., 110,1801-1820, doi:10.1175/1520-0493(1982)110<1801: DEIIC $>2.0 . \mathrm{CO} ; 2$.

Boos, W. R., and Z. Kuang, 2010: Dominant control of the South Asian monsoon by orographic insulation versus plateau heating. Nature, 463, 218-222, doi:10.1038/nature08707.

Bordoni, S., and T. Schneider, 2008: Monsoons as eddy-mediated regime transitions of the tropical overturning circulation. Nat. Geosci., 1, 515-519, doi:10.1038/ngeo248.
Broccoli, A., and S. Manabe, 1992: The effects of orography on midlatitude Northern Hemisphere dry climates. J. Climate, 5, 1181-1201, doi:10.1175/1520-0442(1992)005<1181:TEOOOM >2.0.CO;2.

Broecker, W. S., D. M. Peteet, and D. Rind, 1985: Does the oceanatmosphere system have more than one stable mode of operation? Nature, 315, 21-26, doi:10.1038/315021a0.

Caballero, R., and P. L. Langen, 2005: The dynamic range of poleward energy transport in an atmospheric general circulation model. Geophys. Res. Lett., 32, L02705, doi:10.1029/ 2004GL021581.

— , and J. Hanley, 2012: Midlatitude eddies, storm-track diffusivity, and poleward moisture transport in warm climates. J. Atmos. Sci., 69, 3237-3250, doi:10.1175/JAS-D-12-035.1.

Chen, J., and S. Bordoni, 2014: Orographic effects of the Tibetan Plateau on the East Asian summer monsoon: An energetic perspective. J. Climate, 27, 3052-3072, doi:10.1175/JCLI-D-13-00479.1.

Couhert, A., T. Schneider, J. Li, D. E. Waliser, and A. M. Tompkins, 2010: The maintenance of the relative humidity of the subtropical free troposphere. J. Climate, 23, 390-403, doi:10.1175/2009JCLI2952.1.

Czaja, A., 2009: Atmospheric control on the thermohaline circulation. J. Phys. Oceanogr., 39, 234-247, doi:10.1175/ 2008JPO3897.1.

Dai, A., and K. E. Trenberth, 2002: Estimates of freshwater discharge from continents: Latitudinal and seasonal variations. J. Hydrometeor., 3, 660-687, doi:10.1175/ 1525-7541(2002)003<0660:EOFDFC $>2.0 . \mathrm{CO} ; 2$. 
De Boer, A., J. Toggweiler, and D. Sigman, 2008: Atlantic dominance of the meridional overturning circulation. J. Phys. Oceanogr., 38, 435-450, doi:10.1175/2007JPO3731.1.

Dee, D., and Coauthors, 2011: The ERA-Interim reanalysis: Configuration and performance of the data assimilation system. Quart. J. Roy. Meteor. Soc., 137, 553-597, doi:10.1002/ qj. 828 .

Delcroix, T., C. Hénin, V. Porte, and P. Arkin, 1996: Precipitation and sea-surface salinity in the tropical Pacific Ocean. Deep-Sea Res. I, 43, 1123-1141, doi:10.1016/ 0967-0637(96)00048-9.

Emanuel, K. A., J. D. Neelin, and C. S. Bretherton, 1994: On largescale circulations in convecting atmospheres. Quart. J. Roy. Meteor. Soc., 120, 1111-1143, doi:10.1002/qj.49712051902.

Emile-Geay, J., M. A. Cane, N. Naik, R. Seager, A. C. Clement, and A. van Geen, 2003: Warren revisited: Atmospheric freshwater fluxes and "Why is no deep water formed in the North Pacific." J. Geophys. Res., 108, 3178, doi:10.1029/ 2001JC001058.

Fekete, B. M., C. J. Vörösmarty, and R. B. Lammers, 2001: Scaling gridded river networks for macroscale hydrology: Development, analysis, and control of error. Water Resour. Res., 37, 1955-1967, doi:10.1029/2001WR900024.

Ferreira, D., J. Marshall, and J.-M. Campin, 2010: Localization of deep water formation: Role of atmospheric moisture transport and geometrical constraints on ocean circulation. J. Climate, 23, 1456-1476, doi:10.1175/2009JCLI3197.1.

Gill, A. E., 1980: Some simple solutions for heat-induced tropical circulation. Quart. J. Roy. Meteor. Soc., 106, 447-462, doi:10.1002/ qj. 49710644905 .

Held, I. M., 1983: Stationary and quasi-stationary eddies in the extratropical troposphere: Theory. Large-Scale Dynamical Processes in the Atmosphere, B. Hoskins and R. Pearce, Eds., Academic Press, 127-168.

- and B. J. Soden, 2006: Robust responses of the hydrological cycle to global warming. J. Climate, 19, 5686-5699, doi:10.1175/ JCLI3990.1.

— - M. Ting, and H. Wang, 2002: Northern winter stationary waves: Theory and modeling. J. Climate, 15, 2125-2144, doi:10.1175/ 1520-0442(2002)015<2125:NWSWTA > 2.0.CO;2.

Hoskins, B. J., and D. J. Karoly, 1981: The steady linear response of a spherical atmosphere to thermal and orographic forcing. J. Atmos. Sci., 38, 1179-1196, doi:10.1175/1520-0469(1981)038<1179: TSLROA $>2.0 . \mathrm{CO} ; 2$

Kaspi, Y., and T. Schneider, 2013: The role of stationary eddies in shaping midlatitude storm tracks. J. Atmos. Sci., 70, 25962613, doi:10.1175/JAS-D-12-082.1

Lehner, B., K. Verdin, and A. Jarvis, 2008: New global hydrography derived from spaceborne elevation data. Eos, Trans. Amer. Geophys. Union, 89, 93-94, doi:10.1029/2008EO100001.

Molnar, P., W. R. Boos, and D. S. Battisti, 2010: Orographic controls on climate and paleoclimate of Asia: Thermal and mechanical roles for the Tibetan Plateau. Annu. Rev. Earth Planet. Sci., 38, 77-102, doi:10.1146/annurev-earth-040809-152456.

Neelin, J. D., 1988: A simple model for surface stress and low-level flow in the tropical atmosphere driven by prescribed heating. Quart. J. Roy. Meteor. Soc., 114, 747-770, doi:10.1002/ qj.49711448110.

Newman, M., G. N. Kiladis, K. M. Weickmann, F. M. Ralph, and P. D. Sardeshmukh, 2012: Relative contributions of synoptic and low-frequency eddies to time-mean atmospheric moisture transport, including the role of atmospheric rivers. J. Climate, 25, 7341-7361, doi:10.1175/JCLI-D-11-00665.1.
Nilsson, J., P. L. Langen, D. Ferreira, and J. Marshall, 2013: Ocean basin geometry and the salinification of the Atlantic Ocean. J. Climate, 26, 6163-6184, doi:10.1175/JCLI-D-12-00358.1.

O'Gorman, P. A., and T. Schneider, 2008: The hydrological cycle over a wide range of climates simulated with an idealized GCM. J. Climate, 21, 3815-3832, doi:10.1175/2007JCLI2065.1.

Peixoto, J. P., and A. H. Oort, 1983: The atmospheric branch of the hydrological cycle and climate. Variations in the Global Water Budget, A. Street-Perrott et al., Eds., Springer, 5-65.

$\longrightarrow$, and - 1992: Physics of Climate. American Institute of Physics, 520 pp.

Philander, S. G., 1990: El Niño, La Niña, and the Southern Oscillation. Academic Press, 293 pp.

Reid, J. L., 1953: On the temperature, salinity, and density differences between the Atlantic and Pacific Oceans in the upper kilometre. Deep-Sea Res., 7, 265-275.

_ 1979: On the contribution of the Mediterranean Sea outflow to the Norwegian-Greenland Sea. Deep-Sea Res. I, 26, 11991223, doi:10.1016/0198-0149(79)90064-5.

Rienecker, M. M., and Coauthors, 2011: MERRA: NASA's ModernEra Retrospective Analysis for Research and Applications. J. Climate, 24, 3624-3648, doi:10.1175/JCLI-D-11-00015.1.

Rodwell, M. J., and B. J. Hoskins, 1996: Monsoons and the dynamics of deserts. Quart. J. Roy. Meteor. Soc., 122, 1385-1404, doi:10.1002/qj.49712253408.

$\longrightarrow$, and - 2001: Subtropical anticyclones and summer monsoons. J. Climate, 14, 3192-3211, doi:10.1175/1520-0442(2001)014<3192 SAASM $>2.0 . \mathrm{CO} ; 2$.

Schneider, T., P. A. O'Gorman, and X. J. Levine, 2010: Water vapor and the dynamics of climate changes. Rev. Geophys., $\mathbf{4 8 ,}$ RG3001, doi:10.1029/2009RG000302.

Seager, R., and Coauthors, 2007: Model projections of an imminent transition to a more arid climate in southwestern North America Science, 316, 1181-1184, doi:10.1126/science.1139601.

—, N. Naik, and G. A. Vecchi, 2010: Thermodynamic and dynamic mechanisms for large-scale changes in the hydrological cycle in response to global warming. J. Climate, 23, 4651-4668, doi:10.1175/2010JCLI3655.1.

— , H. Liu, N. Henderson, I. Simpson, C. Kelley, T. Shaw, Y. Kushnir, and M. Ting, 2014: Causes of increasing aridification of the Mediterranean region in response to rising greenhouse gases. J. Climate, 27, 4655-4676, doi:10.1175/JCLI-D-13-00446.1.

Singh, M. S., and P. A. O'Gorman, 2012: Upward shift of the atmospheric general circulation under global warming: Theory and simulations. J. Climate, 25, 8259-8276, doi:10.1175/ JCLI-D-11-00699.1.

Takahashi, K., and D. S. Battisti, 2007: Processes controlling the mean tropical Pacific precipitation pattern. Part II: The SPCZ and the southeast Pacific dry zone. J. Climate, 20, 5696-5706, doi:10.1175/2007JCLI1656.1.

Trenberth, K. E., D. P. Stepaniak, and J. M. Caron, 2002: Accuracy of atmospheric energy budgets from analyses. J. Climate, 15, 33433360, doi:10.1175/1520-0442(2002)015<3343:AOAEBF>2.0.CO;2.

_ L. Smith, T. Qian, A. Dai, and J. Fasullo, 2007: Estimates of the global water budget and its annual cycle using observational and model data. J. Hydrometeor., 8, 758-769, doi:10.1175/JHM600.1.

— , J. T. Fasullo, and J. Mackaro, 2011: Atmospheric moisture transports from ocean to land and global energy flows in reanalyses. J. Climate, 24, 4907-4924, doi:10.1175/2011JCLI4171.1.

Vörösmarty, C., B. Fekete, M. Meybeck, and R. Lammers, 2000: Geomorphometric attributes of the global system of rivers at 30-minute spatial resolution. J. Hydrol., 237, 17-39, doi:10.1016/ S0022-1694(00)00282-1. 
Warren, B. A., 1983: Why is no deep water formed in the North Pacific? J. Mar. Res., 41, 327-347, doi:10.1357/ 002224083788520207.

Weaver, A., C. Bitz, A. Fanning, and M. Holland, 1999: Thermohaline circulation: High-latitude phenomena and the difference between the Pacific and Atlantic. Annu. Rev. Earth Planet. Sci., 27, 231-285, doi:10.1146/annurev.earth.27.1.231.

Webster, P. J., 1981: Mechanisms determining the atmospheric response to sea surface temperature anomalies. J. Atmos. Sci., 38, 554-571, doi:10.1175/1520-0469(1981)038<0554:MDTART>2.0.CO;2.
—, V. O. Magaña, T. Palmer, J. Shukla, R. Tomas, M. Yanai, and T. Yasunari, 1998: Monsoons: Processes, predictability, and the prospects for prediction. J. Geophys. Res., 103, $14451-$ 14 510, doi:10.1029/97JC02719.

Zaucker, F., T. F. Stocker, and W. S. Broecker, 1994: Atmospheric freshwater fluxes and their effect on the global thermohaline circulation. J. Geophys. Res., 99, 12 443-12 457, doi:10.1029/ 94JC00526.

Zweng, M. M., and Coauthors, 2013: Salinity. Vol. 2, World Ocean Atlas 2013, NOAA Atlas NESDIS 74, 39 pp. 